\title{
The Loop Current: Observations of Deep Eddies and Topographic Waves
}

\author{
Peter Hamilton \\ MEAS, North Carolina State University, Raleigh, North Carolina \\ AMY BOWER AND HEATHER FUREY \\ Woods Hole Oceanographic Institution, Woods Hole, Massachusetts \\ ROBERT LEBEN \\ Colorado Center for Astrodynamics Research, University of Colorado Boulder, Boulder, Colorado \\ PAULA PÉREZ-BRUNIUS \\ Centro de Investigación Científica y de Educación Superior, Ensenada, Baja California, Mexico
}

(Manuscript received 19 October 2018, in final form 4 February 2019)

\begin{abstract}
A set of float trajectories, deployed at 1500- and 2500-m depths throughout the deep Gulf of Mexico from 2011 to 2015, are analyzed for mesoscale processes under the Loop Current (LC). In the eastern basin, December 2012-June 2014 had >40 floats per month, which was of sufficient density to allow capturing detailed flow patterns of deep eddies and topographic Rossby waves (TRWs), while two LC eddies formed and separated. A northward advance of the LC front compresses the lower water column and generates an anticyclone. For an extended LC, baroclinic instability eddies (of both signs) develop under the southwardpropagating large-scale meanders of the upper-layer jet, resulting in a transfer of eddy kinetic energy (EKE) to the lower layer. The increase in lower-layer EKE occurs only over a few months during meander activity and LC eddy detachment events, a relatively short interval compared with the LC intrusion cycle. Deep EKE of these eddies is dispersed to the west and northwest through radiating TRWs, of which examples were found to the west of the LC. Because of this radiation of EKE, the lower layer of the eastern basin becomes relatively quiescent, particularly in the northeastern basin, when the LC is retracted and a LC eddy has departed. A mean west-to-east, anticyclone-cyclone dipole flow under a mean LC was directly comparable to similar results from a previous moored LC array and also showed connections to an anticlockwise boundary current in the southeastern basin.
\end{abstract}

\section{Introduction}

The Loop Current (LC) enters the Gulf of Mexico through the Yucatan Channel (sill depth $2000 \mathrm{~m}$ ), and exits through the Florida Straits as the Florida Current, which is depth limited to $800 \mathrm{~m}$. The LC is topographically constrained on its western side for latitudes less than $25^{\circ} \mathrm{N}$ by the Campeche Bank slope, and in the east, north of $24^{\circ} \mathrm{N}$, by the steep west Florida slope. It dominates the eastern Gulf basin through irregular northward extensions (Sturges and Leben 2000) that shed major anticyclonic eddies (diameters $200-400 \mathrm{~km}$ )

Corresponding author: Peter Hamilton, peter_hamilton@ ncsu.edu or rings that translate westward into the western Gulf, eventually dissipating over the Mexican western slope region. Shedding intervals are highly variable with 9-11 months prominent in the 20-yr altimetry sea surface height (SSH) records (Hall and Leben 2016), which, along with satellite observations of sea surface temperature (SST) and ocean color, have been principal sources for LC studies (e.g., Schmitz 2005; Walker et al. 2011).

Based on current profile data, the LC and the Gulf can be divided into two layers. The upper layer, which encompasses the LC and LC eddies, above $800-1200 \mathrm{~m}$, is stratified with large vertical shears, and the lower layer, below $\sim 1000 \mathrm{~m}$, is very weakly stratified with nearly depth-independent velocities that are usually not coherent with the upper-layer (Hamilton 1990, 2007, 2009; 
Hamilton et al. 2016a). It is usual to take the depth of the $6^{\circ} \mathrm{C}$ isotherm as the interface between the two layers (Bunge et al. 2002; Hamilton et al. 2018), which has a mean depth of $800 \mathrm{~m}$ - the depth of the Florida Strait sill. Upper-layer Yucatan Channel inflow brings various water masses from the Caribbean and Atlantic into the Gulf including the minimum salinity Antarctic Intermediate Water (AAIW) layer at $\sim 750 \mathrm{~m}$, and the Subtropical Underwater (SUW) salinity maximum layer. The latter characterizes the core of the LC and LC eddies at $\sim 150 \mathrm{~m}$ (Hamilton et al. 2018; Nowlin 1972). Below $\sim 1200 \mathrm{~m}$, the almost homogeneous North Atlantic Deep Water (NADW) is input from the deep western Caribbean (Sturges 2005).

LaCasce (2017) discusses the effects of bottom slopes on the barotropic and first baroclinic modes of ocean currents. He finds that the change in bottom boundary condition from flat bathymetry to sloped produces an enhanced surface mode with near-zero velocities at the bottom that is consistent with a larger deformation radius than the Rossby scale of the first baroclinic flatbottom mode. Bottom slopes stabilize large baroclinic vortices such as LC eddies (LaCasce 1998). EOF analyses of velocities from deep-water moorings in the Gulf conform to this model very well, with surface intensified modes that decay to zero at $\sim 700-800 \mathrm{~m}$, and either a barotropic mode in the LC (Hamilton et al. 2016a) or farther west, a bottom-intensified mode consistent with topographic Rossby waves (TRW; Hamilton 2009). The two modes often account for $>90 \%$ of the subinertial variance (Hamilton 2009). Abyssal depths in the Gulf have weak bottom slopes that nonetheless are sufficiently large for enhanced surface mode theory to apply (LaCasce 2017). As the LC intrudes toward the northwest, abyssal topographic slopes are weak in the south, but become stronger over the Mississippi Fan (Fig. 1c), which acts as a TRW waveguide directing energy toward the Sigsbee escarpment (Hamilton 2009).

In 2009, a comprehensive array consisting of nine full depth moorings, seven near-bottom moorings, and 25 pressure-equipped inverted echo sounders (PIES) was deployed for 2.5 years in the central and eastern part of the eastern basin with the aim of mapping LC eddy detachments and separations (referred to as the LC mapping array in the following). This was supplemented by two mooring transects across the Campeche Bank slope deployed in Mexican waters (Sheinbaum et al. 2016). Details are given in the study reports Hamilton et al. (2014) and by Hamilton et al. (2016a). A separation is defined as when a detached LC eddy moves off into the western Gulf, and the LC retreats rapidly to the south (Leben 2005). Detachment of a LC eddy from an extended LC may be followed by a reattachment, and these detachment-reattachment events may occur multiple times before separation. An example is the separation of eddy Franklin (Gulf LC eddies are named by an industry group) in 2010 (Hamilton et al. 2016a). The following scenario was established by the separations of three eddies (Ekman, Franklin, and Hadal): the LC extends into the eastern basin and develops largescale southward propagating meanders over deep water on the southward-flowing limb of the current, with wavelengths $\sim 300 \mathrm{~km}$ and periods $\sim 40-100$ days. These meanders amplify through baroclinic instability that generates deep lower-layer cyclones and anticyclones that propagate southwestward across the neck of LC, eventually effecting an eddy detachment. Donohue et al. (2016a) analyzed the baroclinic instability mechanism and showed that the barotropic eddies and the LC jet meanders obtained their kinetic energy (KE) from the potential energy of the uplifted upper-layer density surfaces of the jet. Typical signatures of baroclinic instability were observed, such as the quarter wavelength or $90^{\circ}$ phase lead of the deep cyclones and anticyclones over the surface-layer meander troughs and crests. Energy transfer to the lower-layer took place over intervals of a few months just prior to and during detachments, even though the LC extension time scale was 6 months or more (Donohue et al. 2016a; Hamilton et al. 2016a). The resulting barotropic flows under the LC dominate the total eddy KE (EKE) of the water column, both in the mean and on an event basis (Hamilton et al. 2016a).

Among the unanswered questions that arose from the analysis of the fixed LC array data concern the fate of the deep eddies, the origin of deep disturbances that trigger baroclinic instability and the amplifying meanders of the jet (Donohue et al. 2016a), and the role of topography in controlling LC extensions and configurations. The limited spatial extent of the mooring/PIES array meant that the fate of deep eddies that moved toward the northwest was not observed. It is unknown whether these eddies maintain their rotational integrity or dissolve into TRWs that radiate northwestward toward the Sigsbee escarpment, where deep, bottomintensified flows $\left(\sim 50-90 \mathrm{~cm} \mathrm{~s}^{-1}\right)$ have been observed south of the Mississippi delta (Hamilton and LugoFernandez 2001). An analogy is deep radiation from Gulf Stream meanders in the North Atlantic (Hogg 2000; Malanotte-Rizzoli et al. 1995). Donohue et al. (2016a) had some indication that deep eddies from the northeast corner of the basin had the right phase lead to trigger the meanders. Other deep eddy initiations are possible by the LC itself. Le Hénaff et al. (2012), from a modeling study, suggest that LC flow over the broad ridge of the Mississippi Fan could generate deep cold cyclones by potential vorticity (PV) conservation. 
17 January 2012 - 27 April 2015

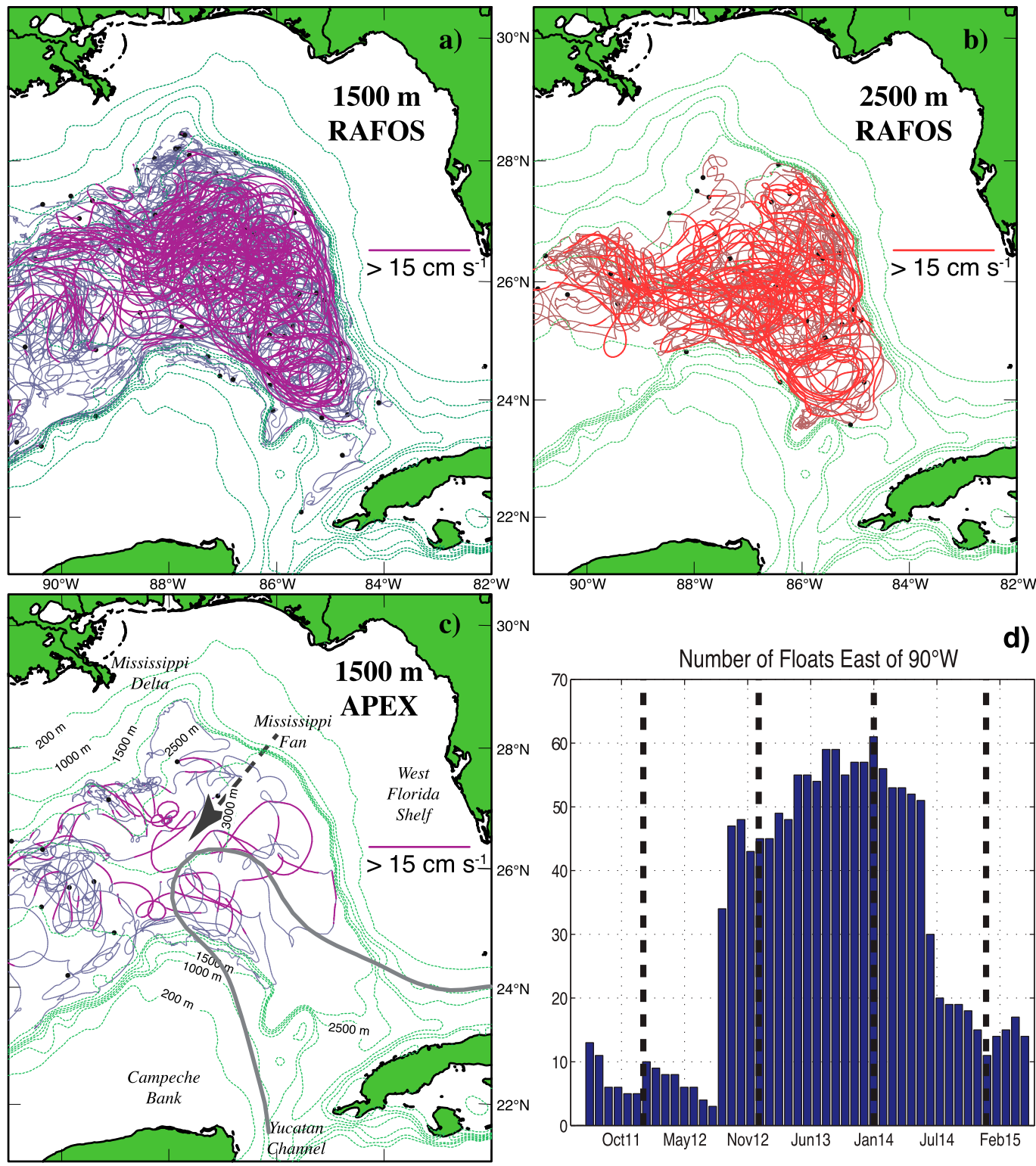

FIG. 1. Float tracks (a) 1500-m RAFOS, (b) 2500-m RAFOS, and (c) 1500-m APEX profiling floats equipped with RAFOS units. Track color conventions are blue-tinged/purple and brown-tinged/red for 1500- and 2500-m floats, respectively. Black dots denote end of the tracks. Saturated (purple and red) colored track segments have thicker lines and have speeds greater than $15 \mathrm{~cm} \mathrm{~s}^{-1}$. (d) The monthly mean numbers of floats east of $90^{\circ} \mathrm{W}$. Labels in (c) indicate geographic features referred to in the text, and the mean position of the Loop Current front given by the 17-cm SSH contour (thick gray line) for the interval with monthly float numbers $>40$ (December 2012July 2014).

There are examples of lower-layer anticyclones being generated by an extending LC in the dataset that is the focus of this study.

A recent observational study employing RAFOS floats at 1500 and $2500 \mathrm{~m}$, deployed throughout the deep basins of the Gulf, allows further investigation of deep flows under the LC. Details may be found in the study report (Hamilton et al. 2016b), as well as in PérezBrunius et al. (2018), Hamilton et al. (2018), and Furey et al. (2018). A total of 121 isobaric RAFOS floats deployed at $1500 \mathrm{~m}$, and 31 at $2500 \mathrm{~m}$, produced 194 float years of location, deep velocity, and temperature data. The extensive nature of these Lagrangian data allows investigation of deep eddies under the LC, changes in 
area-averaged deep EKE, as well as flow patterns over a much wider area than was possible with the fixed mooring array. Furthermore, the July 2011-May 2015 interval with floats in the eastern Gulf encompassed the growth and shedding of LC eddies Icarus, Jumbo, Kraken, and Lazarus, extending the number of events observed by the moored array (Ekman, Franklin, and Hadal). The same Lagrangian data have been used to show deep mean flow patterns and statistics throughout the Gulf (Pérez-Brunius et al. 2018), provide a basinwide census of eddies, and describe deep eddy formation in the western Gulf from LC eddy transits and boundary current instabilities (Furey et al. 2018). The eastern basin is the focus of this paper.

Section 3 describes the LC intrusion and eddy separation events that occurred during the four years of deep observations that extend the number of LC eddy detachments over those observed by the earlier mooring/ PIES experiment. Section 4 concentrates on analysis of deep baroclinic instability eddies, anticyclones that develop under the leading edge of an advancing LC, and TRWs remote from the LC. Section 5 is the discussion of the results and summary.

\section{Data}

A total of 152 RAFOS floats (121 ballasted for $1500 \mathrm{~m}$, and 31 floats for $2500 \mathrm{~m}$ ) had useable missions spanning the period between July 2011 and June 2015. Record lengths for each float varied between 7 and 730 days. In addition, six APEX profiling floats with RAFOS technology were also deployed in the same region and period, with a parking depth at $1500 \mathrm{~m}$ and vertical profiles scheduled every 14 days. This interval is greater than the Lagrangian integral time scale of $\sim 5$ days for the deep Gulf (Hamilton et al. 2016b), and the $\sim 6 \mathrm{~h}$ required for an instrument to measure a profile and return to its parking depth is too short to influence the trajectories. Comparisons of surface locations at a completion of a profile and the closest deep locations from acoustic tracking show minimal displacements. Therefore, APEX track data are treated as continuous and equivalent to a 1500-m RAFOS float. All floats were acoustically tracked using an array of four sound source moorings, resulting in position, temperature and pressure records three times a day. All data were transmitted by Iridium Satellite Communications when the RAFOS float surfaced at the end of its mission, and every two weeks when the APEX float surfaced after sampling a vertical profile. For more details on the dataset, see Hamilton et al. (2016b). This dataset is available at the NOAA/AOML subsurface float observations archive (http://www.aoml.noaa.gov/phod/float_traj/index.php).
The locations are smoothed and filtered using the objective method of successive corrections (Pedder 1993) and resampled at regular 8-h intervals. The tracks are split if there are gaps of greater than 5 days. The method removes signals with periods less than $30 \mathrm{~h}$, so removing any inertial and tidal oscillations, which, however, are very weak at depths of $1500 \mathrm{~m}$ and greater in this dataset. Very short records, less than 10 days, are discarded. The resulting tracks are given in the spaghetti diagrams of Fig. 1. Note the relative abundance of high speeds $\left(>15 \mathrm{~cm} \mathrm{~s}^{-1}\right)$ under the LC and in a band stretching northwestward toward Mississippi delta region. The latter is particularly prominent for the $2500-\mathrm{m}$ floats (Fig. 1b), which, with one exception, were all deployed east of $90^{\circ} \mathrm{W}$, showing a main pathway for EKE to be transmitted toward the eastern Gulf.

Estimates of flows in circular or elliptical eddies proceeds as follows. The floats that have trajectories within the eddy over a fixed time interval are identified; the standard deviation ellipse is calculated from the velocities and plotted on a map, where the ellipse center is the mean location of the float velocities. The velocity scale is adjusted so that the ellipse perimeter encloses a large majority of the float trajectories. Depending on the distribution of float tracks, the ellipse is divided into equal sectors, and possibly further subdivided in the radial direction, with the aim of adequate coverage and DOF in most of the subdivisions. The velocities and locations are averaged for each subarea to generate a spatially variable mean eddy circulation for the given time interval. Further circulation characteristics of the eddy are then estimated from the velocity field. Examples of eddy circulations using this method are given in section 4.

Although all processed records are used to investigate the horizontal and time variability of the eastern Gulf, the interval with a consistently large number of float tracks is between 10 December 2012 and 3 July 2014, with a maximum of 77 , and an average of 42 floats per day within the region east of $90^{\circ} \mathrm{W}$. A histogram of mean monthly float numbers shows relatively high values during this interval (Fig. 1d).

To track the locations of the LC and LC eddies simultaneously with the deep flow events, gridded $\left(0.25^{\circ} \times 0.25^{\circ}\right)$ altimetry products from the Colorado Center for Astrodynamics Research (CCAR) are used to provide SSH (Leben 2005; Leben et al. 2002). Satellite altimeters cannot directly measure absolute SSH because of imprecise knowledge of the marine geoid at length scales commensurate with the Gulf. Deriving SSH measurements from SSHA provided by the altimeters rely on estimates of the mean dynamic topography from a data assimilative model (Kantha et al. 2005; 

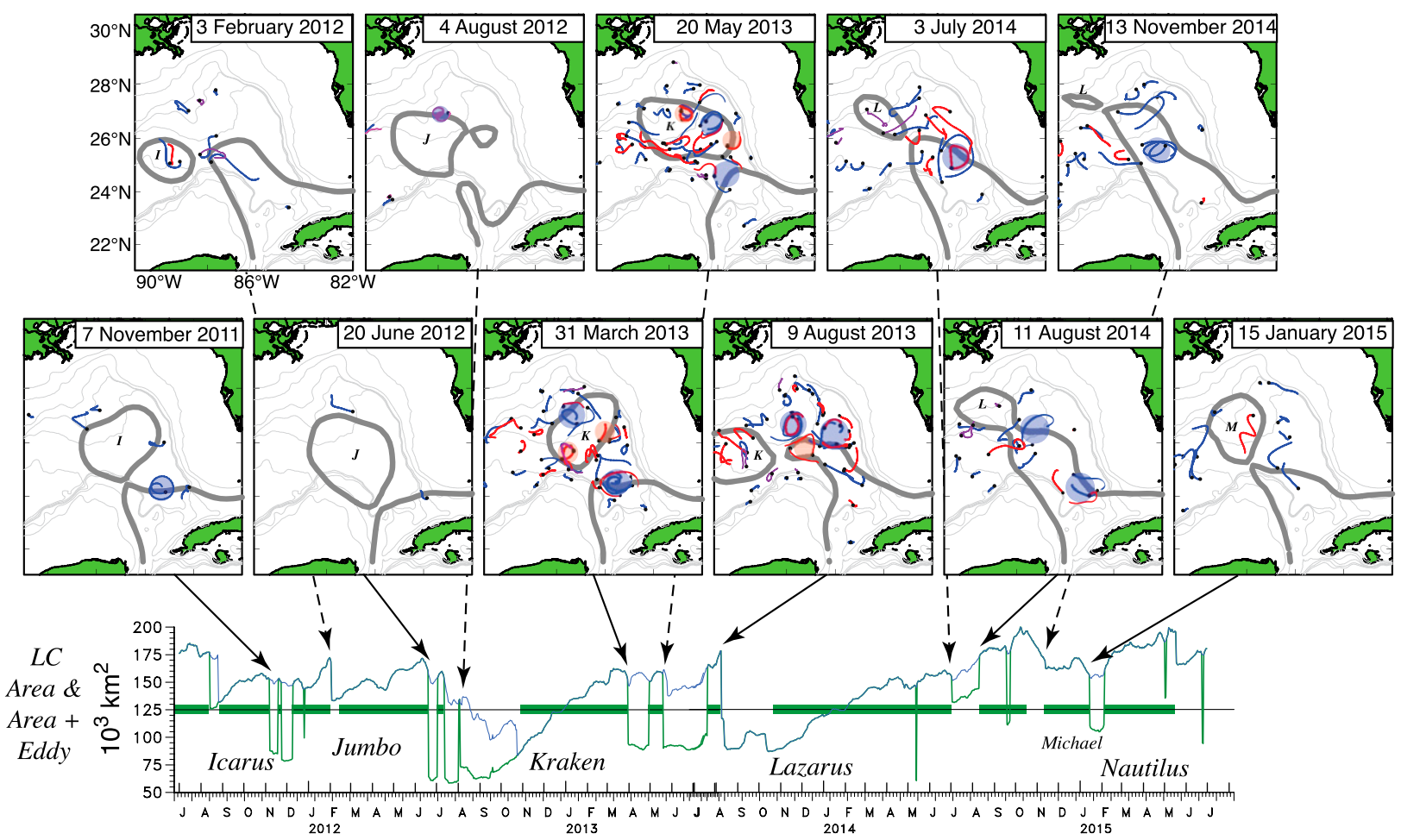

FIG. 2. (bottom) Major LC eddy events in the Gulf of Mexico, where the area of the LC (green line) and the area of the LC plus detached eddy (blue line) from the 17-cm (CCAR) SSH contour before it completely crosses a line from the delta to the northeast Yucatan. Intervals, when the LC is extending into the Gulf before a detachment, are given by the thick green line segments on the abscissa. (top) Maps keyed to the time series show detachment and separation events, where the thick gray line is the 17-cm SSH contour, and 15-day float trajectories, centered on the map date, are shown for 1500- (blue) and 2500-m (red) RAFOS and 1500-m APEX (purple). The location of the end of each segment is shown as a black dot. Examples of anticyclonic (clockwise) and cyclonic (anticlockwise) loops are indicated by light red and blue under shading circles, respectively. Bathymetry is the same as Fig. 1.

Leben et al. 2002) in the case of the CCAR data product. Altimeter data from a total of five operational satellites [Jason-1, Ocean Surface Topography Mission (OSTM)/ Jason-2, Envisat, CryoSat-2, and Satellite with Argos and Altika (SARAL)/AltiKa] were available during the time period of the study, with ground track repeat intervals of 10,17 , and 35 days. In a comparison of the CCAR product, the similar gridded product from AVISO (Le Traon et al. 1998), and dynamic height from Argo/ APEX CTD floats (Hamilton et al. 2018), the CCAR product was found to be better tuned to the mesoscale eddy scales of the LC, whereas AVISO generally produces smoother daily fields particularly in the western Gulf. The well-established SSH 17-cm contour is used to delineate the location of the LC and LC eddy fronts (Leben 2005). The 17-cm contour from the mean SSH field for the December 2012-July 2014 interval is given in Fig. 1c.

Because of the two-layer nature of the deep Gulf, even deep temperatures measured by an isobaric float at $1500 \mathrm{~m}$ are influenced by upper layer eddies, even though currents at these depths are generally distinct from and not coherent with upper-layer flows. Hamilton et al. (2018) showed from APEX/Argo CTD profiles that the depth of the $6^{\circ} \mathrm{C}$ isotherm is significantly correlated with temperature measured at $1475 \mathrm{~m}\left(R^{2}=0.61\right)$. Thus, a float temperature record can be used to determine if a location is under a warm or cold upper-layer feature.

\section{LC eddy separation events}

LC eddy separations have been extensively studied from remote observations (SST and SSH) (Leben 2005; Schmitz 2005), and more recently using full water column measurements from a moored array (Donohue et al. 2016a,b; Hamilton et al. 2016a). These float data extend available observations of circulation processes under the LC. LC extensions, eddy detachments and separations during the period of the float observations are given in Fig. 2. Time series of the areas within the 17-cm SSH contours of the LC (north of the Yucatan Channel and west of $82^{\circ} \mathrm{W}$ ), and the LC plus a detached eddy show when detachments and separations occur. 
A LC eddy disappears from the area calculation after it completely crosses the line from the delta to the northeast corner of the Yucatan peninsula. Thus, the difference between the two time series estimates the size of a detached eddy and how long it is present in the eastern Gulf.

The series begins with the first detachment of Icarus occurring in November 2011. The cyclone (emphasized by light blue under shading in Fig. 2) in the 1500-m float track on the 7 November 2011 map is displaced southward from the pinch-off point $\sim 25^{\circ} \mathrm{N}$. After two reattachments, Icarus separates quite far to the west in February 2012. Note the almost linear displacements of the floats under Icarus in the 3 February 2012 map. The LC does not retreat very far (to $\sim 26^{\circ} \mathrm{N}$ ) after the separation, before expanding and forming the aptly named Jumbo by a first detachment in June 2012, in the southwest of the basin, $\sim 23^{\circ} \mathrm{N}$. After two more reattachments, a much-reduced Jumbo finally separates in August 2012. However, it remains in the eastern basin through October 2012 (Fig. 2; lower panel), with the LC in "port to port" mode (small area; south of $24^{\circ} \mathrm{N}$ ), before a small remnant makes it into the western basin where it rapidly dissipates. This behavior is very similar to Franklin in 2010 (Hamilton et al. 2016a) with an initial detachment of a large eddy, with a southern separation point, that eventually reduced in size before dissipating rapidly in the western basin. Only a few float trajectories are available for both Icarus and Jumbo.

The LC begins a fairly quick expansion from its portto-port mode in November 2012 to form Kraken. The first detachment is at the end of March 2013, followed by a reattachment about a month later, and a second detachment in May 2013. There is a strong cyclone displaced southward from the detachment point in the 31 March 2013 map, as well as indications of a sequence of alternating cyclonic and anticyclonic (emphasized by light blue and red under shading, respectively) deep eddies around the periphery of the eddy. Similarly in the 20 May 2013 map, there is strong deep eddy activity with alternating anticyclones and cyclones on the northern side of the eddy that terminate with a cyclone in the detachment region. Kraken begins to move to the west, elongating in an east-west direction. It reattaches to the LC in July 2013, but breaks free in August 2013, with a pinch-off point $\sim 26^{\circ} \mathrm{N}, 88^{\circ} \mathrm{W}$, and quickly departs the eastern basin.

After Kraken, the LC made a moderate retreat (to $25^{\circ} \mathrm{N}$ ) and then began in October 2013 a year-long extension toward the northwest, resulting in one of the largest LC areas ever observed in October 2014, when LC water extended westward from the delta along the lower northern slope, which disrupted industry operations in these regions (Sharma et al. 2016). During this longlasting extension, Lazarus detached in July 2014, but reattached a month later, with the LC continuing to extend toward the northwest. After October 2014, the LC retreated and eventually shed a small inconsequential eddy in November 2014, still named Lazarus, just south of the Mississippi delta. However, the LC was still extended to $27^{\circ} \mathrm{N}$, and formed another temporary eddy (Michael) in the middle of January, which remained in the eastern basin for less than a month before being reabsorbed into the LC. The LC continued to grow after Michael reattached, and eventually a moderate sized eddy (Nautilus) was shed and moved into the western Gulf in May 2015.

The whole of the 20-month interval from the initiation of LC growth after Kraken to the shedding of Nautilus in May 2015 could be considered as one major event, because the initial Lazarus and then Michael did not leave the eastern basin, and the LC continued to extend toward the northwest after both reattachments. Also the shed Lazarus (13 November 2014, map in Fig. 2) was small, unlikely to contain any SUW core, and rapidly dispersed in the eastern part of the western basin (Hamilton et al. 2018). Another consequence of this unprecedented event is that after the departure of Kraken, there is an interval of $\sim 5$ months when there is no LC or LC eddy activity in the northern half of the eastern basin (September 2013-January 2014). Therefore, the lack of surface-layer eddy activity allows analysis of the decay of deep eddies during this quiescent interval over a wide area of the eastern basin.

\section{Analysis}

\section{a. Mean flow fields}

Deep means, variances, and KE over the entire deep Gulf, using float velocities, are given in Pérez-Brunius et al. (2018). Similar results for the eastern basin are derived here using a slightly different method that helps to delineate the escarpment boundary currents, as well as a comparison with Eulerian means and variances from near-bottom current meters. Means and variance ellipses are calculated for $3 / 4^{\circ} \times 3 / 4^{\circ}$ squares at $1 / 2^{\circ}$ latitude and longitude intervals for the interval with the highest number of floats Thus, the averaging squares overlap by $1 / 8^{\circ}$ on each side. Only squares with number of observations $N>30$ are shown. Each float has three observations per day, and to estimate degrees of freedom (DOF) for each square, $N$ is divided by 15 , assuming an integral time scale of 5 days (Hamilton et al. 2016b; PérezBrunius et al. 2018). Parameter $\langle N\rangle=1515 \pm 81$ with an average of 54 floats occupying each square. The locations 


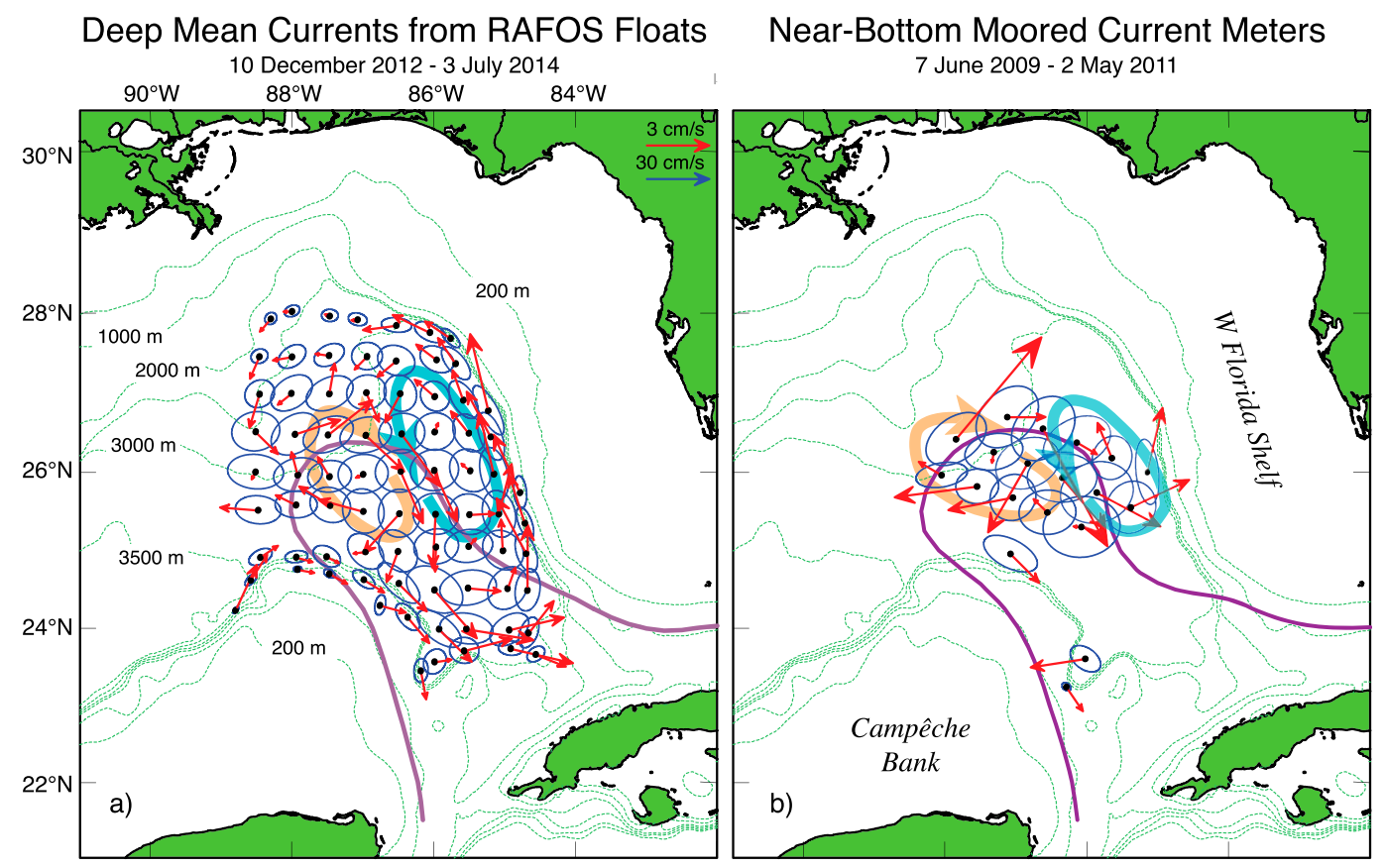

FIG. 3. Mean velocities (red arrow scale) and standard deviation ellipses (blue arrow scale) for (a) floats and (b) current meter subtidal records $100 \mathrm{mab}$, for the indicated intervals. The orange (anticyclonic) and blue (cyclonic) arrows give a sketch of the sense of the deep mean circulations. The thick purple line is the mean location of the $17-\mathrm{cm} \mathrm{SSH} \mathrm{contour} \mathrm{for} \mathrm{each} \mathrm{interval.}$

of the mean vectors in Fig. 3a are the average of all the positions in the square rather than the center of the square, which results in a better representation of boundary currents along steep escarpments. For comparison, 2-yr mean statistics for current meters $100 \mathrm{~m}$ above bottom (mab) from the LC mapping array are given in Fig. 3b. The mean deep circulation from moorings is discussed in more detail in Hamilton et al. (2016a).

Both plots in Fig. 3 show a west-to-east anticyclonecyclone mean flow pair beneath the mean LC (as does Pérez-Brunius et al. 2018). This has been attributed to lower-layer PV conservation:

$$
\frac{D}{D t}\left(\frac{f+\zeta}{h}\right)=0
$$

where $f$ is the Coriolis parameter and $\zeta$ and $h$ are the lower-layer relative vorticity and thickness, respectively; an increase or decrease in $h$ over time will cause a relative increase or decrease in $\zeta$, thus generating cyclonic or anticyclonic relative vorticity, respectively. Therefore, an LC extending toward the northwest that squeezes the lower water column in that direction and increases it on the opposite eastern side will consequently decrease and increase relative vorticity, respectively. The expanded area of the Lagrangian results relative to the mooring array reveals an eastward boundary current around the steep escarpment at the north end of the Campeche Bank that continues around the southern part of the basin, and then merges with and possibly enhances the cyclone along the west Florida slope escarpment (Fig. 3a). The southeastward mean flow at the mooring near the Campeche slope (N4; Hamilton et al. 2016a) is consistent with this boundary current (Fig. 3b). Lagrangian results have lower magnitudes than the Eulerian; however, this is to be expected because of area and time averaging versus time averaging at a point. A mean anticyclonic-cyclonic paired circulation under the LC seems to be a robust feature because it occurs in both Eulerian and Lagrangian velocity data for two different intervals with differing LC eddy-shedding events.

Pérez-Brunius et al. (2018) showed from the RAFOS float database that EKE is much greater by factor $\sim 3$ in the eastern $\left(>80 \mathrm{~cm}^{2} \mathrm{~s}^{-2}\right)$ as compared to the western basin $\left(<30 \mathrm{~cm}^{2} \mathrm{~s}^{-2}\right)$. This is reflected by the high speeds prevalent in Fig. 1. In the west, float speeds average $\sim 5-6 \mathrm{~cm} \mathrm{~s}^{-1}$. Similarly, Furey et al. (2018), using fairly strict criteria, showed from an eddy census that both cyclonic and anticyclonic coherent loops, in the lower layer, were more numerous in the east than in the west, using $90^{\circ} \mathrm{W}$ as the dividing meridian. Per unit trajectory, approximately twice as many eddies were found in the 

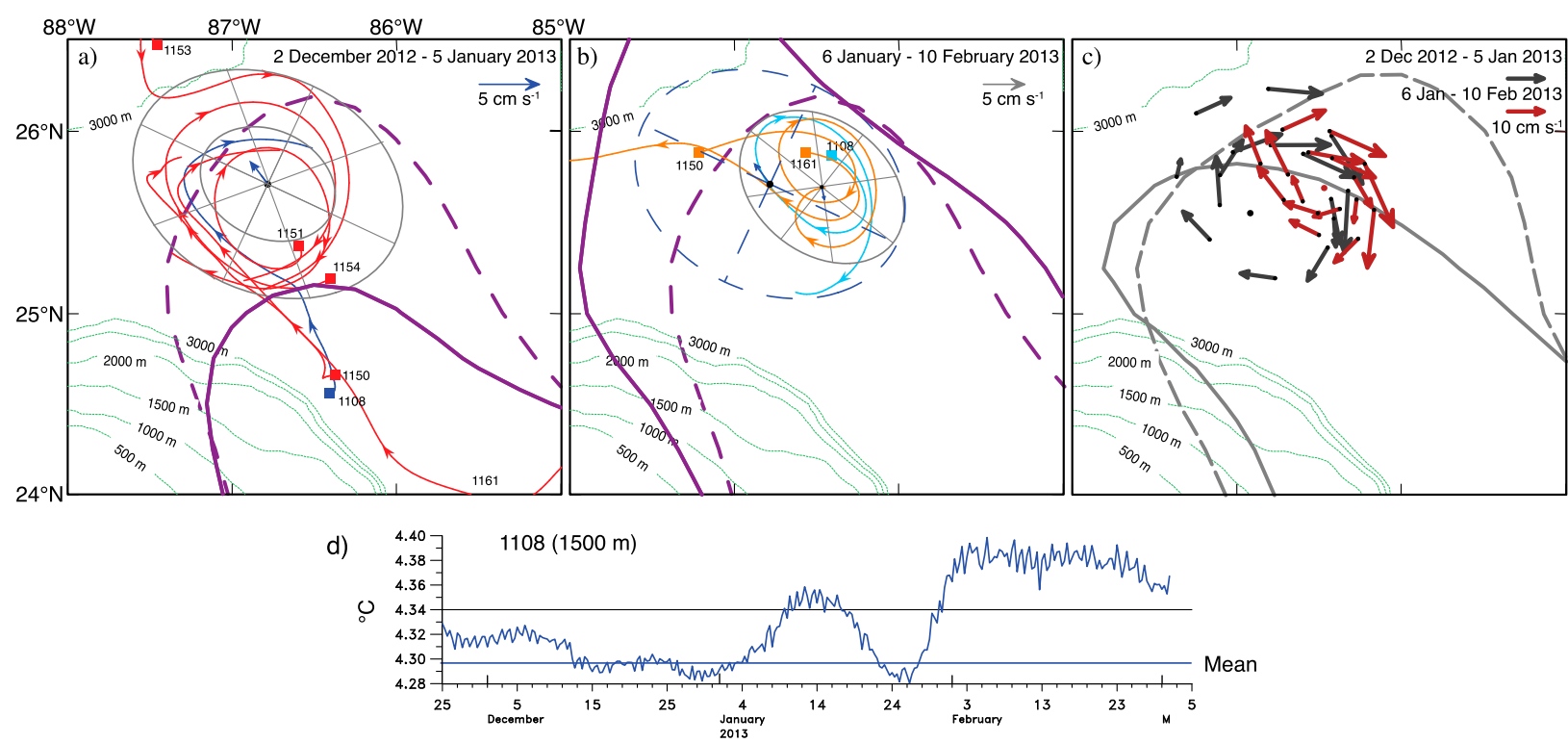

FIG. 4. Composite tracks for an anticyclone (a) the first 35 days and (b) the second 35 days. The standard deviation ellipses are shown with gray solid lines [note scale change between (a) and (b)] and the annular sectors used to average velocities. Red/orange and blue/light blue are 2500- and 1500-m floats, respectively. Trajectory segments begin with a square dot and have arrowheads every 10 days. The standard deviation ellipse from (a) is repeated in (b) (dashed blue lines) with no change of scale to show the relative motion of the center over 35 days and the contraction in area. (c) The resulting averaged velocities for the two intervals where the LC 17-cm contour (gray lines) shown for the midpoint of each interval (19 Dec 2012, solid; 24 Jan 2013, dashed). LC 17-cm SSH contours for 2 Dec 2012 (solid) and 6 Jan 2013 (dashed), and 10 Feb 2013 (solid) are given as thick purple lines in (a) and (b). (d) Time series of float 1108 temperature. Mean of 628-day record is indicated.

east as compared to the west. In the following sections, case studies of two distinct types of deep eddies are discussed, namely, anticyclones generated by an advancing LC, and baroclinic instability eddies associated with the meandering LC jet.

\section{b. Generation of deep anticyclones by an advancing $L C$}

When the LC begins to extend into the Gulf over the nearly level southeastern abyssal plain, the intrusion of the southward sloping pycnocline will cause a compression of the lower layer under the leading edge of the LC front, generating anticyclonic relative vorticity by (1). There are a number of examples in the database of deep anticyclones developing under the early stages of an intruding LC, before other deep eddy activity under the LC becomes dominant. Detecting eddies in Lagrangian tracks depends on whether the float or floats become entrained in the feature, and how long they remain before being ejected or move on to another flow regime. The best example has between three and five floats showing an intensifying anticyclone under a rapidly intruding LC front between December 2012 and February 2013, about three months before the first detachment of Kraken (Fig. 2).

A detailed view of float trajectories in this anticyclone is given in Fig. 4. Because the anticyclone made a move to the east with a decrease in the diameter of the orbits between 2 December 2012 and 10 February 2013, the float trajectories are divided into two 35-day segments. In the first segment, six floats make clockwise circuits of the elliptical eddy, which has a diameter of $\sim 70-120 \mathrm{~km}$ (estimated from the area of the ellipsoid), and rotational periodicities of $\sim 25-30$ days (Fig. $4 a$ ). After early January, three of the floats spiral toward the center and move eastward (Fig. 4b). There is a change in velocity scale between Figs. $4 \mathrm{a}$ and $4 \mathrm{~b}$, however, the EKE $\left[=1 / 2\left(a^{2}+b^{2}\right)\right.$ where $a$ and $b$ are the velocity standard deviation ellipse semimajor and minor axes, respectively] are almost the same $\left(70.4\right.$ and $\left.83 \mathrm{~cm}^{2} \mathrm{~s}^{-2}\right)$. The periodicities in Fig. 4b are $\sim 15-20$ days. Therefore, there is an increase in eddy vorticity $\zeta$ between the first and second intervals of about a factor of 2. Parameter $\zeta$ is $\sim-0.15 f$ in Fig. 4b. This could be explained as being a result of compression of the lower water column as the later anticyclone is more within the LC front than the larger earlier eddy. The estimated $\zeta$ is comparable to Furey et al.'s (2018) deep eddy census values for deep interior eddies throughout the Gulf, using an objective method, though their mean diameters are smaller by about a factor of 2 .

The northward advance of the LC front between the beginning and end of the trajectories accounts for the 


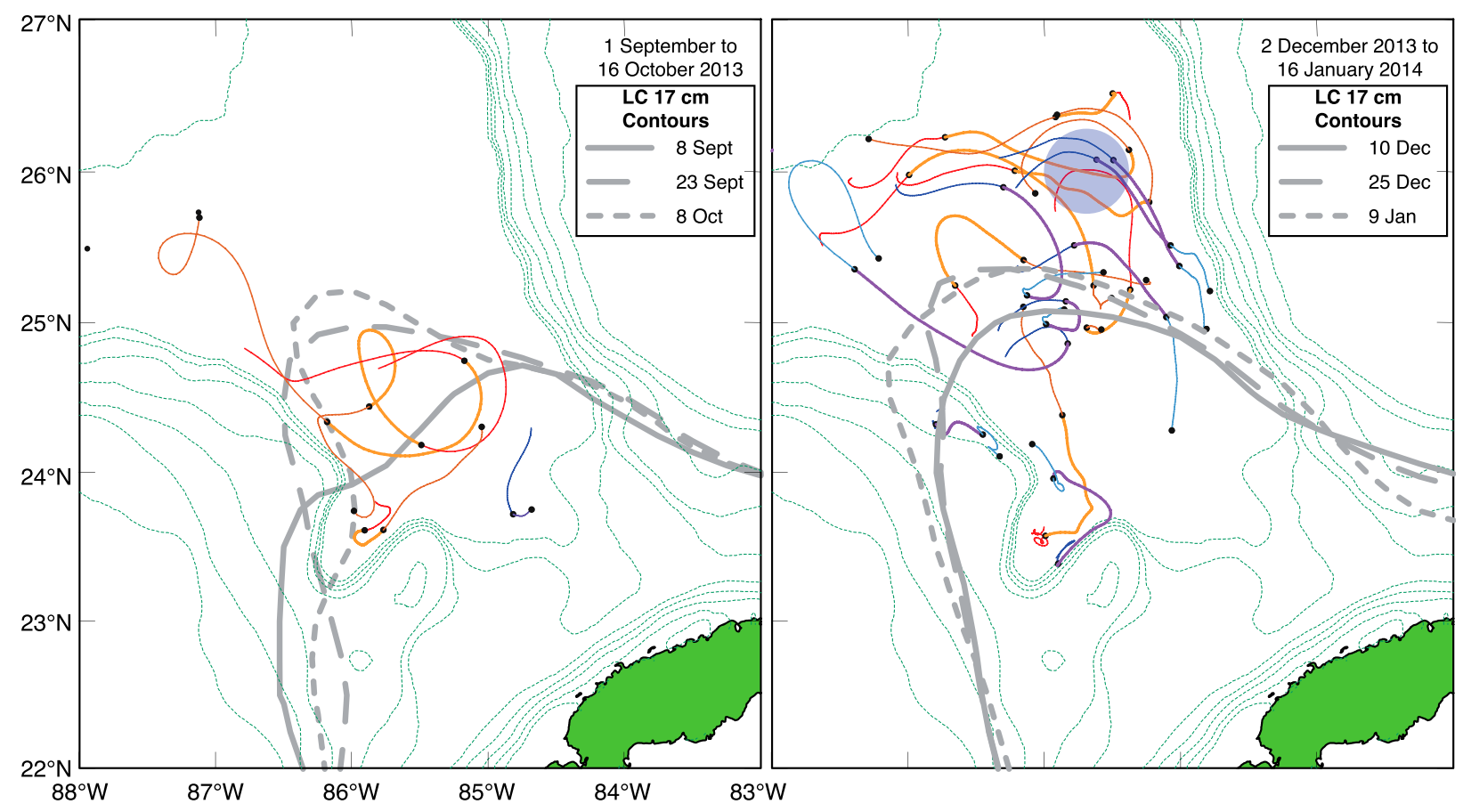

FIG. 5. Examples of leading-edge anticyclones as the LC intrudes into the eastern basin (both for Lazarus). Float trajectories are given in three consecutive 15-day segments, each ending in a black dot for the given intervals. The 2500-m segments progress from red to orange (emphasized) to brown, and 1500-m segments progress from blue to blue magenta (emphasized) to blue-green. Three LC 17-cm SSH contours (thick gray lines) are shown for the midpoint of each segment on each map. In the right-hand panel, the cyclonic loops are indicated by a light blue under shade circle. Bathymetric contours are the same as in Fig. 4.

compression of the lower layer, resulting in the generation of anticyclonic vorticity. There was one 1500-m float (1108) in the constellation in Figs. 4a and 4b, and its temperature (Fig. 4d) reflects the location of the trajectory relative to the cold and warm sides of the LC front. Note that the front slopes down to the south from its surface expression and so the first $50 \mathrm{~km}$ of the northward path before 4 January 2013 are relatively cold, until it enters the anticyclone and the advancing front catches up. The 1500-m temperature reflects the overlying upper-layer circulation and the lower thermocline, rather than the water mass characteristics of the deep eddy, per se (Hamilton et al. 2018).

In Fig. 4c, mean velocity vectors are calculated for the subsectors of the ellipses as shown in Figs. 4a and $4 \mathrm{~b}$. The locations of the mean vectors in the annular subareas are the average of all the velocity positions found in each subarea for the given time intervals. In the first interval, velocities are stronger on the north side, which may explain the movement of the eddy to the east. In the second interval, the velocities are generally larger in the more compact anticyclone where gradients of azimuthal velocities are weak and far from the linear relationship that would be expected for solid body rotation. Maximum speeds are 17.1 and $19.2 \mathrm{~cm} \mathrm{~s}^{-1}$ for the first and second interval, respectively. Moored current meter measurements under the LC (Hamilton et al. 2016a) indicate depth-independent flows below $1000 \mathrm{~m}$, and therefore, with water depths of $\sim 3000 \mathrm{~m}$, these eddy circulations contain considerable kinetic energy.

Other examples of anticyclones under the leading edge of an intruding LC front are given in Fig. 5 for a short-lived advance in September and October 2013, and then for a later intrusion beginning in December 2013 that eventually led to the detachments of Michael and Lazarus (Fig. 2). The anticyclonic loops are shown for several floats for both events, though the second event shows a cyclone forming to the northeast, perhaps indicating that baroclinic instability may be initiating. There is some evidence from different float trajectories that the cyclone persists and moves southward along the eastern LC front, eventually causing a necking down of the LC $\sim 23^{\circ} \mathrm{N}$, but not a detachment, in May 2014. Floats in the two leading edge anticyclones of Fig. 5 leave once the LC front ceases to advance, becomes stationary for a time, or retreats.

\section{c. Baroclinic instability eddies}

The development of deep eddies through baroclinic instability of the east-side jet of the LC was analyzed by 
Donohue et al. (2016a), using PIES and current meters from the LC mapping array. They showed that deep eddies, both cyclones and anticyclones, jointly intensified with meanders of the southward flowing jet with the $90^{\circ}$ phase lead characteristic of baroclinic instability. The amplifying meander troughs that lead to LC eddy detachments (Fig. 2) have their counterparts in the large quasi-stationary meander troughs of the Gulf Stream $\sim 68^{\circ}$ W. Savidge and Bane (1999a) observed the formation of deep cyclones under developing unstable troughs, which they analyzed as cyclogenesis caused by baroclinic instability of the Gulf Stream jet (Savidge and Bane 1999b).

The LC array did not have the resolution $(\sim 50 \mathrm{~km})$ to capture details of deep eddy structures. A good example is the intensification of the cyclone below a meander trough in the southeast, between February and April 2013 that leads to the first detachment of Kraken (Fig. 2; map for 31 March 2013). About five floats were tracked simultaneously in this deep cyclone that allows investigation of its circulation. A sequence of 10-day trajectories are shown at large scale in Fig. 6, where from 3 March 2013, the floats circle at $\sim 120-\mathrm{km}$ diameter, then spiral in toward the center (floats 1108, 1110, and 1123: 13 March-2 April; Fig. 6) with a diameter about half that of 3-13 March, and then spiral out again as Kraken detaches, dispersing to the west after $\sim 20$ April 2013. The center of the cyclone is clearly displaced southeastward from the midpoint of the LC trough, as determined by the SSH contours.

As the 1500-m floats $(1108,1110,1123$, and 1145) enter the cyclone and spiral toward the center, their temperatures decrease because of uplifted isotherms in the cold center of the meander trough (Fig. 6). In the interval 2-12 April 2013, the deep cyclone is positioned partly under the LC, as noted above, and there is a corresponding rise in temperature for the floats while they are in the southern segment of their trajectories. This indicates that the change in depth of the lower thermocline is registered by the temperature of the isobaric floats, at a nominal $1500 \mathrm{~m}$, because of upperlayer LC and peripheral cyclone activity. The true depth of each float differs a little from $1500 \mathrm{~m}$, and therefore it is the relative changes in temperature that are important.

A composite of the five trajectories and the standard deviation ellipse for the float velocities in the interval 3 March-20 April 2013 is given in Fig. 7a. There is sufficient coverage in all quadrants of the ellipse to estimate mean velocities. The subareas for the averaging are indicated, and the resulting velocity vectors are shown in Fig. $7 \mathrm{~b}$. The average number of observations per subarea is $28[11,45]$, or equivalently $\sim 9$ days of float velocities, where there are three observations per day. In Fig. $7 \mathrm{~b}$, the origin of the vectors is the average location of floats in the subarea, not the center of the annular subarea; thus, the distribution of vectors is not quite symmetrical. The result is an elliptical cyclone (approximate diameter $200 \mathrm{~km}$ ) with maximum azimuthal speeds of $\sim 20 \mathrm{~cm} \mathrm{~s}^{-1}$, and eccentricity $e \sim 0.6$. The size and azimuthal speeds are similar to those observed under Gulf Stream meander troughs by Savidge and Bane (1999a) and Andres et al. (2016).

One feature of the velocity field is the relative lack of radial gradients. An eddy in solid body rotation will have a linear gradient in azimuthal velocities with rotation frequency $\omega=0.5 \zeta$, where $\zeta$ is the relative vorticity. The contours of $\zeta$, calculated from the mean velocity vectors, show values of $\sim+0.3 f$ in the center, and $\sim+0.1 f$ on the periphery (Fig. $7 b$ ). This implies rotation periods of $\sim 8-10$ days and $20-25$ days, respectively. This is approximately confirmed by the inner and outer loops in Fig. 7a, and though the radial resolution is poor, it could be concluded that the eddy may not be in solid body rotation. However, the tracks in Fig. 7 are largely in the outer parts of the eddy and there is probably a small core in solid body rotation. Figure $7 \mathrm{~b}$ also shows the ageostrophic velocity components estimated using the universal cokriging method of Pedder (1989). The results show convergences on the north and west sides, and divergences on the south side, and are probably a result of the floats spiraling into the center from the north and out to the south.

There are a number of examples of displaced trough deep cyclones, usually associated with LC eddy detachments. In Fig. 2, Icarus (7 November 2011); Kraken (31 March 2013); and the separation of Kraken (9 August 2013) have characteristic cyclonic eddies on the LC side of a detachment. Anticyclones displaced from meander crests are also present in the data but floats do not seem to remain with anticyclonic features to the same extent as with cyclones. An example is the second detachment of Kraken (Fig. 2; map for 20 May 2013) where the west-to-east anticyclone-cyclone pair along the northern front of the eddy, eventually leads to a splitting of the eddy on May 24 with the smaller eastern section being reabsorbed into the LC. This event shows that even though the eddy has detached, there is continuity in the sequence of deep anticyclones and cyclones trending along the northeastern front toward the southeast, thus connecting the eddy and the LC. This implies that the LC eddy (Kraken) can also develop baroclinic instabilities.

Furey et al. (2018) analyze a 1500-m float that makes four circuits around a deep cyclone in October 2014 over an interval of 51 days and translates southwestward 

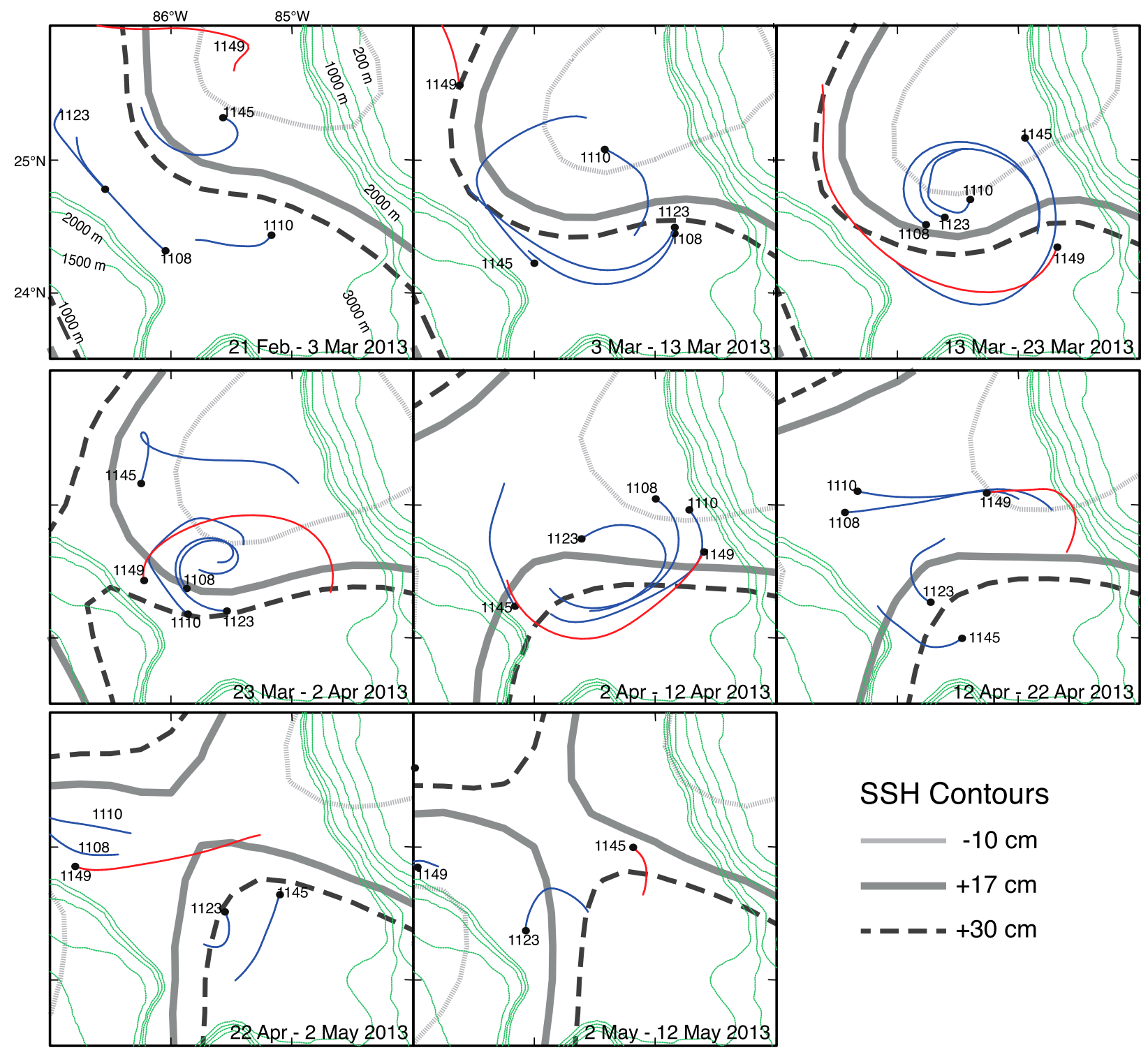

\section{SSH Contours}
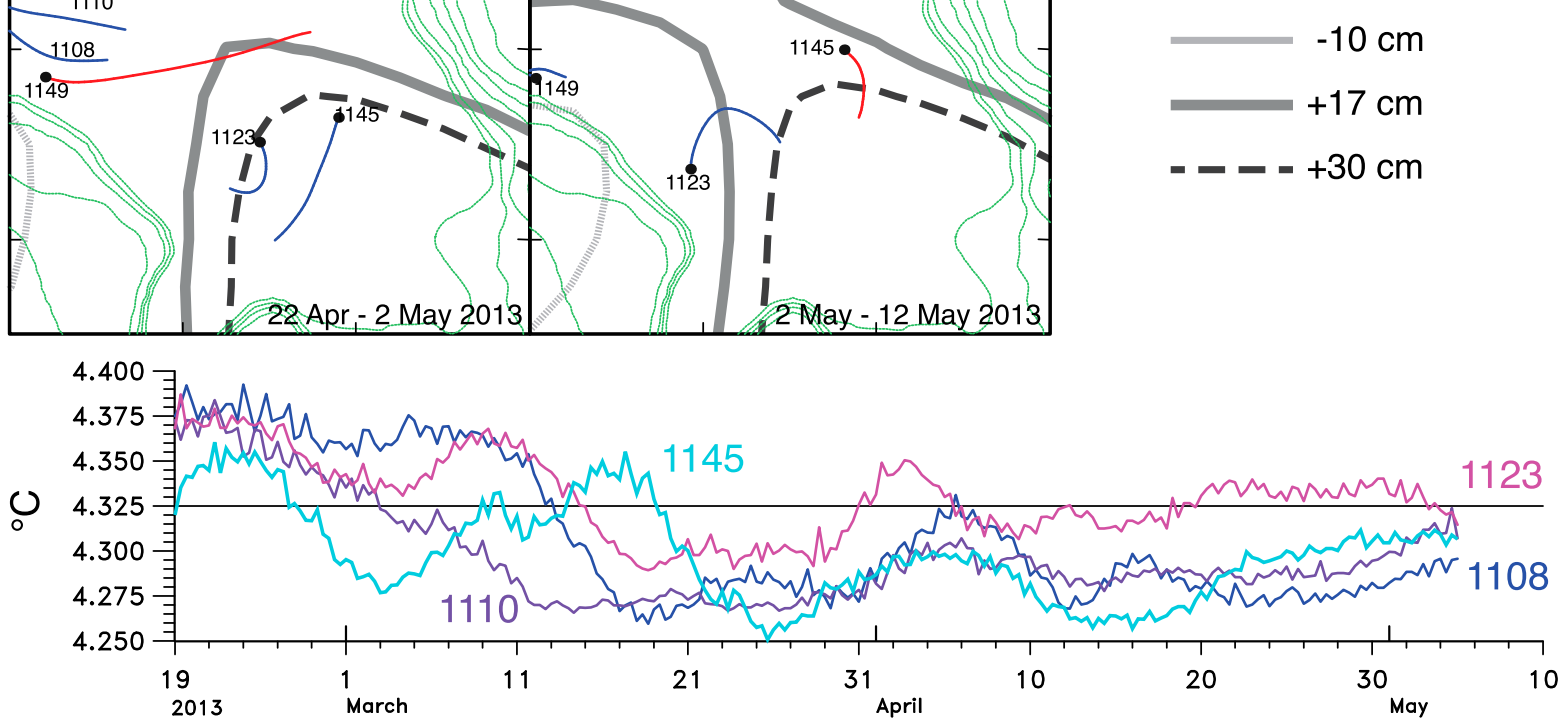

FIG. 6. (top) Sequence of 10-day trajectories for the indicated dates showing the development of a cyclone beneath a LC meander trough. Blue and red tracks are at 1500 and $2500 \mathrm{~m}$, respectively. The end point of each 10-day trajectory is marked with a black dot. Overlaid are CCAR SSH contours for the center day of each interval. (bottom) The time series of 1500-m float temperatures for the interval of the sequence plots. Bathymetry contours are $200 \mathrm{~m}$ and at $500-\mathrm{m}$ intervals. 


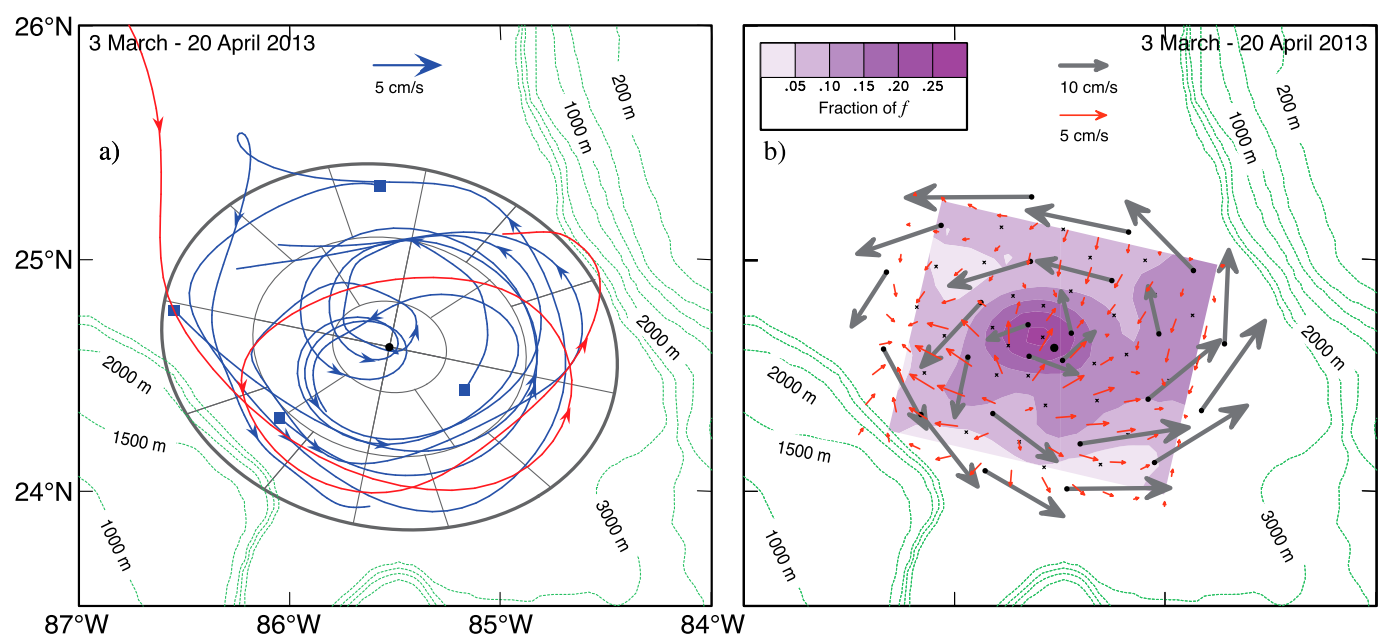

FIG. 7. (a) Composite of float trajectories in the deep LC cyclone for 3 Mar-20 Apr 2013. The standard deviation ellipse of float velocities for the interval is overlaid (blue scale arrow), and subareas of the ellipse for velocity mean calculations are indicated. (b) Mean velocities for the subareas are centered on the average locations of the floats (dark gray arrows and scale). The contour map of relative vorticity is overlaid with ageostrophic vectors (red arrows and scale) calculated from the velocity potential.

under an extended LC (their Fig. 4). This is an important example of a deep eddy propagating across the LC similar to the case studies in Donohue et al. (2016a). The cyclone can be seen directly under the LC in the 13 November 2014 map in Fig. 2. Azimuthal speeds were $\sim 25 \mathrm{~cm} \mathrm{~s}^{-1}$, rotational periods $\sim 13-14$ days, and eddy radii $\sim 40-55 \mathrm{~km}$. The eddy did not effect a detachment perhaps because it was not out of phase with the weak meanders of the highly intruded LC, and thus did not strengthen over the four observed circuits.

\section{d. Deep EKE variability}

One of the important results of the LC mapping array study was the relatively short interval, compared to the time scale of a LC intrusion, in which EKE was transferred to the lower layer through baroclinic instability (Donohue et al. 2016a; Hamilton et al. 2016a). For the three eddy separations, the large increases in deep EKE took place in the few months immediately preceding or during LC eddy detachments events. The deep float study allows time series of EKE to be constructed for two more events; the detachments of Kraken and Lazarus, as well as allowing investigation of EKE levels over a wider area than just under the LC.

The eastern basin is divided into three equal area rectangles: under the mean LC or southeast, northeast, and an extension to the northwest and the Sigsbee escarpment (Fig. 8a). Sixteen-day windows are advanced by one day to cover the 18 -month interval. For each 16-day window, velocities from all floats in the rectangle are accumulated and averaged to generate a mean velocity vector and corresponding mean kinetic energy, as well as a total eddy kinetic energy. Because the statistics are derived for large areas, straightforward areal averages over 16-day intervals may be aliased by clusters of floats (e.g., see the next section on TRWs). To minimize aliasing, the velocities are first averaged into daily means. For each day in the window, floats closer than $30 \mathrm{~km}$ are replaced by an average velocity and location before the overall area average is calculated. The deep eddy decorrelation scale is $\sim 30-50 \mathrm{~km}$ (Donohue et al. 2006). Averages accounting for clustering reduce the number of effective daily observations by between $0 \%$ and $10 \%$, with only small changes if $50 \mathrm{~km}$ is used instead of $30 \mathrm{~km}$. The DOF are estimated from the number of daily observations per 16-day interval, accounting for clustering, divided by 3 , which is the integral time scale for the eastern Gulf (Hamilton et al. 2016b). The DOF for each rectangle are given in Fig. 8a, and the time series of the magnitude of the standard error of the mean in Fig. 8b. Time series, including the area of the LC with the area of the LC plus the area of the LC eddy, identical to Fig. 2, are given in Fig. 8b. After the last detachment of Kraken, the LC stays in a retreated port-to-port mode between the latter half of August and November 2013 (e.g., see LC maps in Fig. 8c).

The center panels of Fig. $8 \mathrm{~b}$ show the area-averaged velocities, accounting for clustering, of the float observations that occur within each of the rectangles for each sliding 16-day window, centered on the time series date. The velocity magnitudes under the LC (black vectors) show large fluctuations just prior to the first detachment of Kraken and then later in May 2013 when the eddy was 

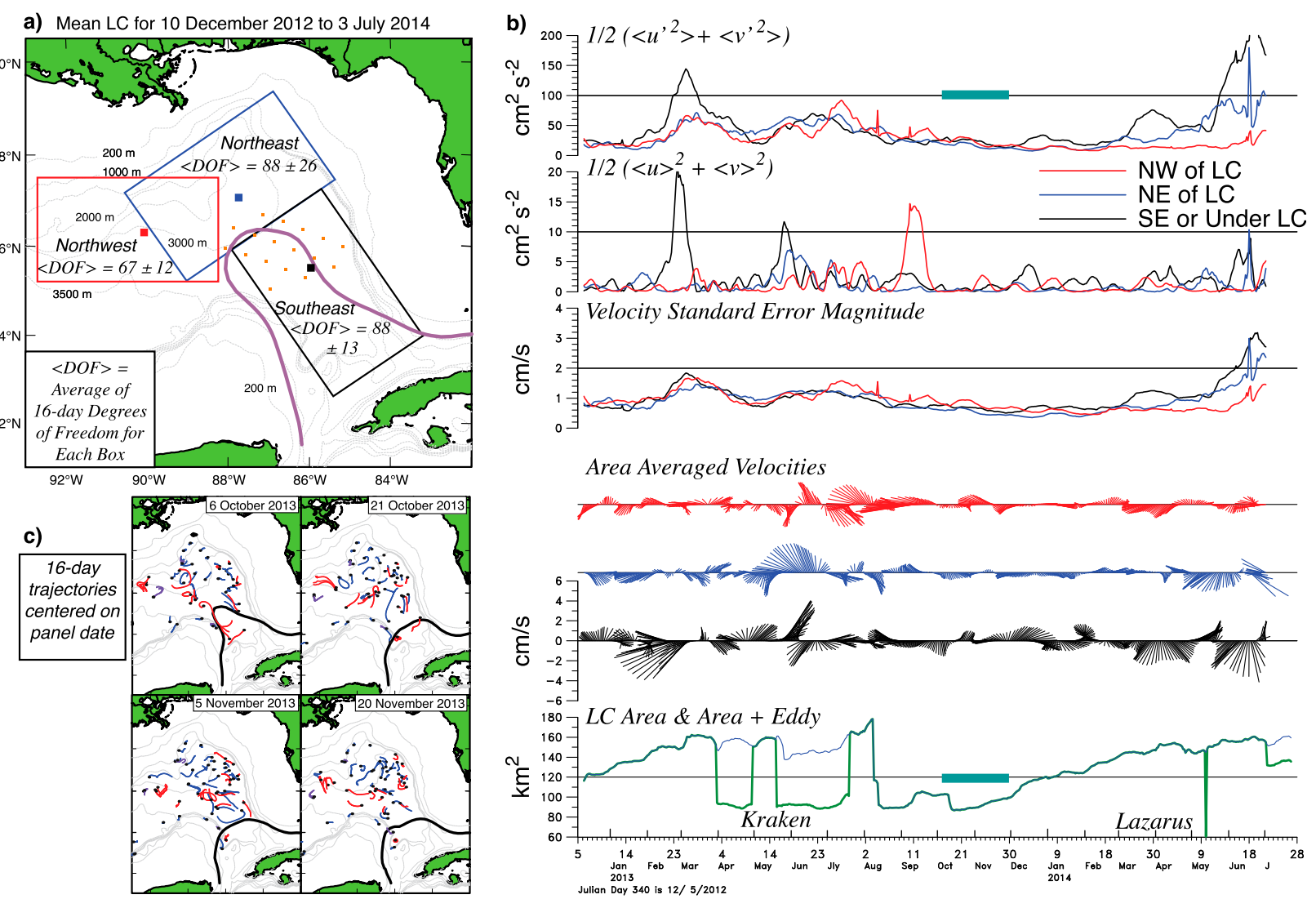

FIG. 8. (a) Color-coded averaging areas for float velocities, where the average degrees of freedom $\langle$ DOF $\rangle$ (with standard deviations) in the 16-day intervals are given, and the average center locations of all the observation in each box are given by the solid squares. The mean LC front location for the interval is given by the thick purple line. The small orange squares show the locations of moorings from the LC dynamics experiment with deep current meters 100 mab. (b) Time series of LC area, area-mean velocities, velocity standard error magnitude, and mean KE and EKE, color-coded by the rectangles in (a). (c) Four consecutive 16-day panels showing a low-energy regime in the northeast, centered on the map date. Conventions as in Fig. 2. The time interval is marked on the abscissa of the time series in (b).

moving to the west (see maps in Fig. 2). The magnitudes also increase just before the detachment of Lazarus (June 2014). In the northeast area (blue vectors), magnitudes are less except when the eddy or the northern front of an extended LC begin to show signs of developing baroclinic instability (e.g., May 2013 for Kraken, and May 2014 for Lazarus; Fig. 2). In the northwestern rectangle (red vectors), there are substantial westward area-averaged flows in July and August 2013 that could be contributions to the Sigsbee deep boundary current. The next-to-the-top panel shows these magnitudes in terms of total mean KE, calculated from the areaaveraged velocities.

The top panel of Fig. 8b shows the EKE calculated from the variances of velocities that occur in each rectangle for each 16-day interval. The high EKE during the eddy detachments is noted, and is similar to that found for LC eddy detachments between 2009 and 2011 from the LC mapping array, situated mostly within the Under LC (southeast) rectangle (see Hamilton et al. (2016a), their Fig. 2). When Kraken separated and began to move rapidly westward, the northeast rectangle EKE increased (July 2013). After August 2013, with the LC retreated and with Kraken out of the eastern basin, the EKE showed an exponential decay, particularly in the northeast rectangle when the $\mathrm{LC}$ is far to the south. This decrease in northeast rectangle variances lasted through February 2014, when a growing Lazarus begins to influence the region. This decay, when the LC is not present, could have a component from frictional dissipation, but it is more likely to be due to westward radiation out of the region by TRWs. The latter explanation is supported by the large peaks of EKE in June and July 2013 in the northwestern rectangle that lag the post-Kraken peaks in the two eastern areas. Moreover, the northwestern area July EKE peak precedes the strong westward mean-flow event in August and September 2013 that implies transfer of TRW energy into the mean flow as discussed in DeHaan and Sturges (2005), and theoretically analyzed by Mizuta and Hogg (2004). 
The trajectories in the Fig. $8 \mathrm{c}$ maps, during the low energy period (Fig. 8b), indicate that when deep eddies were not present north of the LC, the floats tended to have small-amplitude quasi-rectilinear oscillations, largely in place, consistent with wave trains that transport momentum but not mass. Because baroclinic instability is the major source of deep EKE, the implication is that this deep EKE is dissipated through radiating TRWs that remain after the LC eddy has departed. (Hamilton 2009).

\section{e. Topographic Rossby waves}

Deep current meter observations over gentle abyssal slopes in the northern Gulf have been analyzed in terms of propagating TRWs (Hamilton 1990, 2007, 2009). Similar mooring observations north of the Gulf Stream also show the presence of TRW wave trains (Hogg 2000; Thompson 1977) propagating southwestward toward Cape Hatteras (Pickart 1995). Characteristics of TRWs at a given frequency (Rhines 1970) are that the fluctuations are rectilinear, the group velocity is directed along the major principal axis such that shallow water is on the right, and the direction of the group velocity vector to the topographic gradient is to a good approximation a function of frequency only, such that the highest frequencies supported by the bottom slope and deep stratification are parallel to the topographic gradient vector. Low-frequency waves have higher group speeds than those at higher frequencies. Thus, trains of dispersive TRWs that cover a substantial frequency band passing through a local region will produce rather complex fluctuations that change with time and are largely rectilinear rather than rotational. Oey and Lee (2002), using a numerical model, interpreted the flows along the Sigsbee escarpment as being caused by propagating TRWs emanating from the LC and transiting LC eddies.

Furey et al. (2018) identified 49 separate eddies from the float tracks of which $60 \%$ (30) were located in the interior of the basins. Coherent loops only occupied $4 \%-7 \%$ (depending on detection criteria of three or two loops, respectively) of the total number of float days (194 years). Examination of the time series in the interior of the eastern basin tends to show a majority of rather chaotic nonlooping motions. Examples are the panels of Fig. 9a, where the region to the north of a retracted LC and east of the departing Kraken, shows mostly straight-line segments with varying directions. Of particular note are the three floats moving in coherent rectilinear patterns, marked as TRW just south of the delta.

For five months, from 28 August 2013 to 25 January 2014, three 2500-m floats (1151, 1250, and 1254) oscillated in the vicinity of the 3000-m isobath south of the delta (Fig. 9b). The standard deviation ellipse for all the velocities from these three floats, for this interval, shows the major axis approximately aligned with the isobath for the mean location. The mean principal axis of the three velocity time series is $112.6^{\circ}$ [degrees true $\left.\left({ }^{\circ} \mathrm{T}\right)\right]$, whereas the direction of the isobaths from a least squares plane fit to the depths using a $100-\mathrm{km}$ length scale is $107.6^{\circ} \mathrm{T}$, implying that there is propagation upslope as the group velocity vector lies in the second quadrant for axes aligned with the topography. A more detailed examination of the float trajectories for the first 90 days using 10-day segments is given in Fig. 10. The three floats remain very close together with an approximate return to their initial positions at $\sim 60$ days. For the 30 days after $\sim 27$ October, the oscillations have a shorter period and are directed more across the isobaths (Fig. 10; bottom panel). In December and January, the floats become more dispersed but revert to paths more along the isobaths (not shown). Similar kinds of rectilinear oscillations of clusters of deep floats were analyzed by Price and Rossby (1982) for the western North Atlantic $\left(31^{\circ} \mathrm{N}, 70^{\circ} \mathrm{W}\right)$ and were shown to be consistent with dispersion relation for barotropic topographic planetary waves. Price and Rossby (1982) had nine cooscillating floats and so were able to estimate relative vorticity $\zeta$ and show that the motions satisfied conservation of PV to a high degree. For the three floats in Fig. 9b, velocity locations are close together and are often nearly colinear as a function of time. Therefore estimates of $\zeta$ are not possible or are error prone.

In a coordinate system defined by the upslope direction $\left(14.6^{\circ} \mathrm{T}\right)$ of the gradient of PV (includes $\beta$ ), the Reynolds stress is negative for planetary waves with an upslope component of group velocity (Bower and Hogg 1992). Reynolds stresses, calculated from $\left\langle u^{\prime} v^{\prime}\right\rangle$ in the PV gradient coordinate system, are negative for all three float velocity time series, and consistent with the principal axes being in the second quadrant with $\sim 180^{\circ}$ phase differences between $u^{\prime}$ and $v^{\prime}$. The latter indicates transverse fluctuations caused by radiating Rossby waves.

The velocity records, in the coordinate system aligned with the principal axis of the variance ellipse in Fig. 9b, from the three floats for this TRW interval show both longer- and shorter-period fluctuations (Fig. 11a). The longer $\sim 2$-month periods are evident in the component plots, but are not resolved (i.e., outside the cone of influence; Torrence and Combo 1998) by the wavelet power spectra (Fig. 11b). There is power at $\sim 25-30$ days, similar to spectral peaks found from current meters in this region (Hamilton 2007, 2009), but there are also shorter periods of $\sim 10-16$ days in October. There is a 


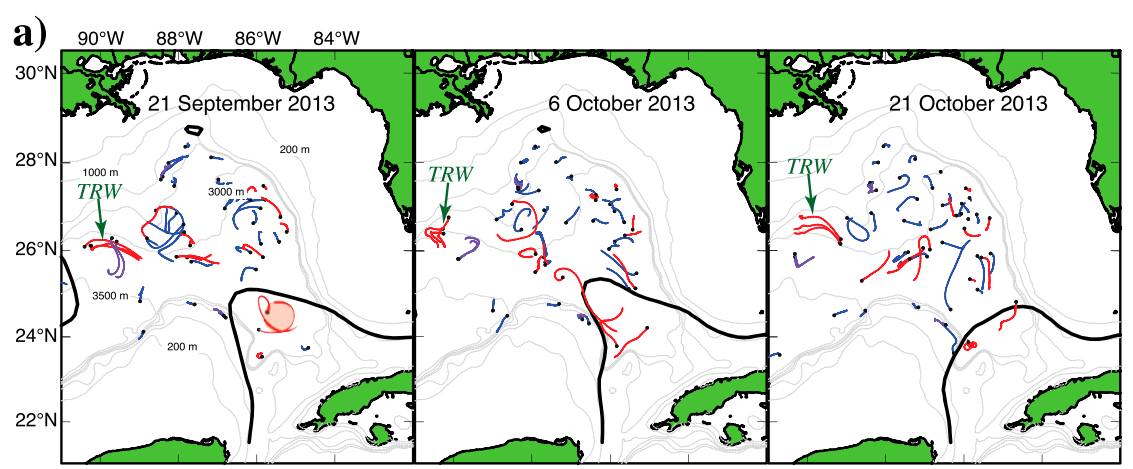

b) $1151 \quad 1250125411521153 \quad 28$ August 2013 - 25 January 2014

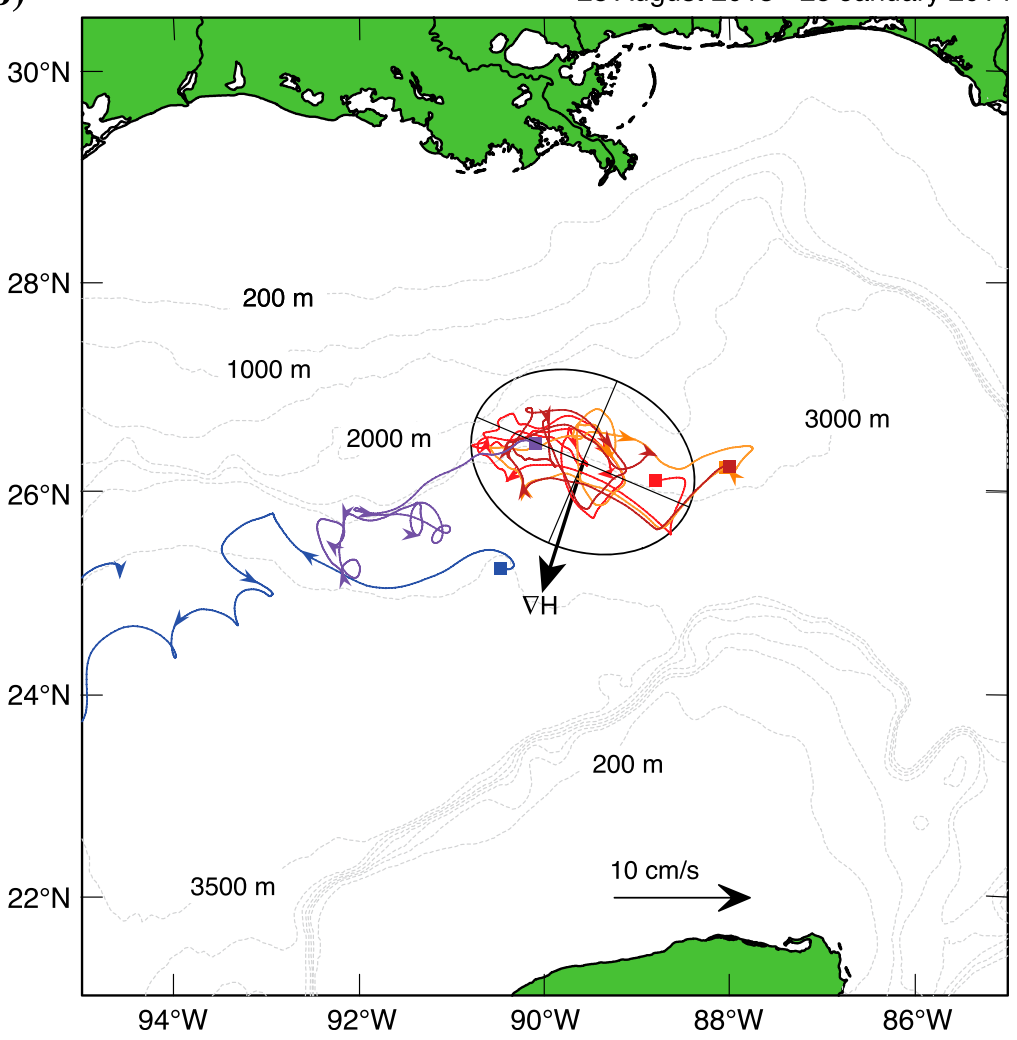

FIG. 9. (a) Sixteen-day float tracks centered on the dates shown in each panel. Conventions as in Fig. 2. TRW trajectories are marked and shown in more detail for the indicated interval in (b), where arrowheads are every 20 days. Initial positions on 28 Aug 2013 marked by solid squares. The standard deviation velocity ellipse, centered on the average locations of floats 1151, 1250 and 1254, is given for the indicated period. The direction of the mean PV gradient is given by the $\nabla \mathbf{H}$ vector.

burst of short-period fluctuations $\sim 3-5$ days (not resolved by the wavelet analysis) toward the end of December for float 1151 that occur when the float is adjacent to the steep slope of the Sigsbee escarpment, in the northwest part of the trajectories. Short-period TRWs have been observed in this region previously (Hamilton 2007) and may have differing origins to the longer-period waves. The presence of a fairly broad band of energetic frequencies indicates wave generation by deep eddy dispersion rather than a resonance with upper-layer eddies or meanders (Pickart 1995). The trajectories of two other 1500-m floats (1152 and 1153) that were a little farther west during this same interval, can be interpreted as due to a southwestward mean flow superimposed on oscillations of $\sim 20$ days across the isobaths (Fig. 9b). It is not clear if these trajectories are a downstream consequence of the TRWs observed farther east. 


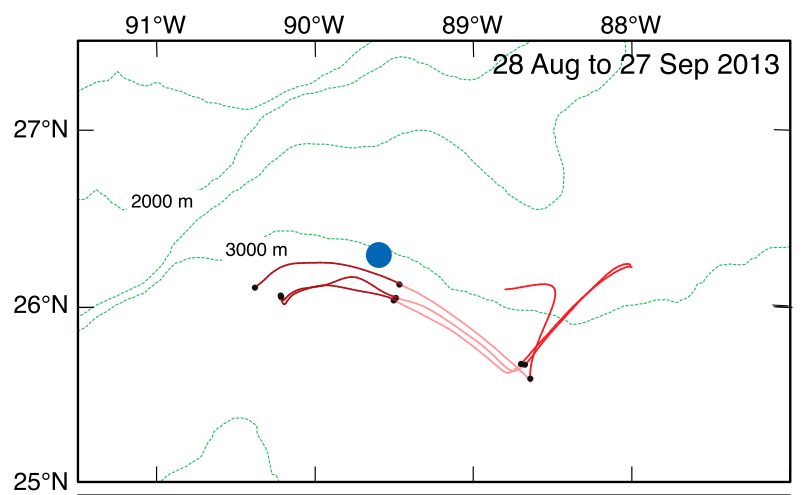

$25^{\circ}$
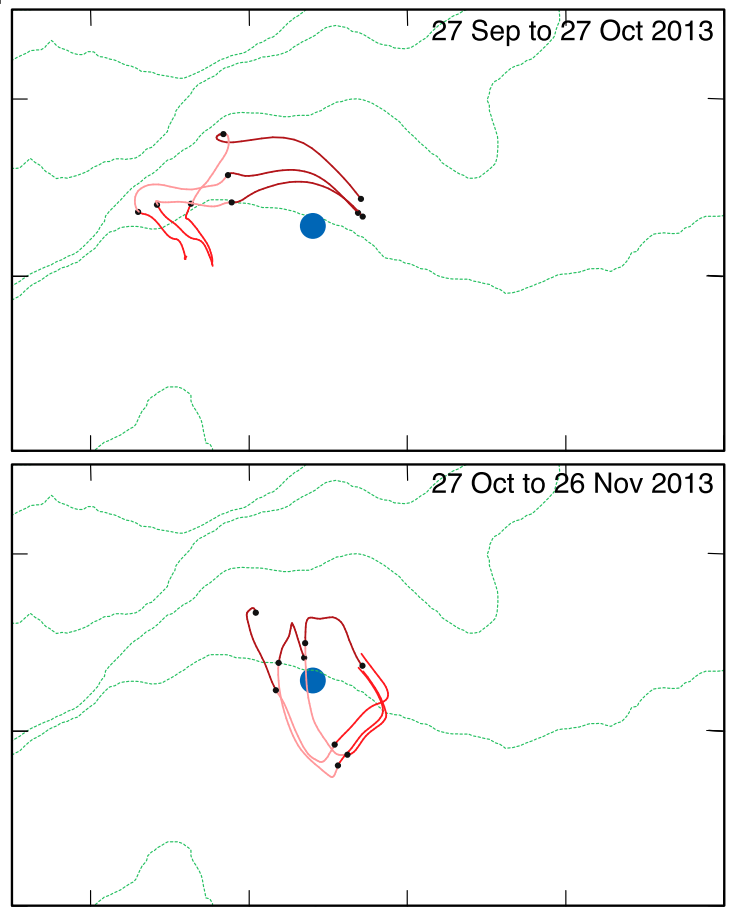

FIG. 10. Consecutive 30-day sequences of trajectories of 2500-m floats 1151,1250 , and 1254. Each 30 -day segment is divided into three 10-day trajectories with end points indicated by black dots. The $0-10,10-20$, and $20-30$ days in each plot are indicated by red, orange, and brown colored tracks. The blue dot is the location of the center of the ellipse in Fig. 9b.

Another example of floats (four at $1500 \mathrm{~m}$ and two at $2500 \mathrm{~m}$ ) clustering around the $3000-\mathrm{m}$ isobath south of the delta (Fig. 12a) can be observed for an earlier interval, from 24 January to 30 March 2013. The discussion above refers to an interval after Kraken had separated and departed, and the overall EKE in the region north of the LC was decreasing. The earlier interval analyzed here is just prior to the first detachment of Kraken (note the necking down of the $17-\mathrm{cm} \mathrm{SSH}$ contour for 30 March 2013; Fig. 12a), and is a period of high EKE under the LC (Fig. 8) from developing baroclinic instabilities. The TRW fluctuations here are less definitive as the clustering is not as strong as later, and the interval is much shorter. The principal axis of the velocity standard deviation ellipse is directed into the third quadrant, relative to the mean slope, with the group velocity having a component downslope (Fig. 12a). However, the bathymetry of the Mississippi Fan is quite variable in direction in this region and the mean may not be significant. It can be seen that the individual trajectories in Fig. 12a often follow the trend of the local isobaths (e.g., floats 1135 and 1153). The velocities from these six floats are given in Fig. 12b, and it can be seen that the velocity fluctuations are much less coherent than in Fig. 11a, though again the records show a range of periodicities. Figure 12c shows the EKE spectra for three of the records in Fig. 12b. Float 1147 has higher and lower frequencies than the other two (1138 and 1161), which have a resolved peak periods of $\sim 17$ days.

\section{Discussion and summary}

Deep circulation processes related to the LC and LC eddy shedding in the eastern Gulf have been investigated using a database of 194 float years of deep RAFOS trajectories over an interval of four years. There were 121 and 31 deployments of 1500- and 2500-m floats, respectively. During the period of densest coverage (December 2012-July 2014), the LC shed two LC eddies (Kraken and Lazarus), and a number of deep eddy phenomena were documented.

A number of examples of anticyclones developing under a LC intruding from retracted position were examined and attributed to PV conservation as the lower layer is squeezed by the advancing upper layer. Topography is not an important factor when the LC is south of the Mississippi Fan $\left(<26^{\circ} \mathrm{N}\right)$, as the abyssal plain in the southeastern Gulf has very weak slopes. The best example in December 2012 (Fig. 4), where several floats orbited a leading edge anticyclone, showed the deep eddy intensifying as the LC intruded and compressed the lower layer. It is noteworthy that these anticyclones appear not to persist once the LC stops or slows its intrusion, as the floats in the eddy rapidly depart and no external floats are entrained into the last known location of the anticyclone. It may be speculated that once the lower-layer compression stops, the eddies rapidly disperse into radiating TRWs (LaCasce 1998). To the authors' knowledge, these are the first observations of this type of PV conservation anticyclone in the deep LC.

The other main category of deep eddies is associated with an extended LC that has generated southward propagating large meanders (dominant periods $\sim 40$ 100 days, wavelengths $\sim 300 \mathrm{~km}$; Hamilton et al. 2016b) on the north and east sides of the flow over deep water. The joint amplification of meanders and deep anticyclones 


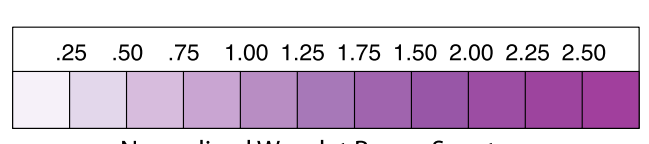

Normalized Wavelet Power Spectrum
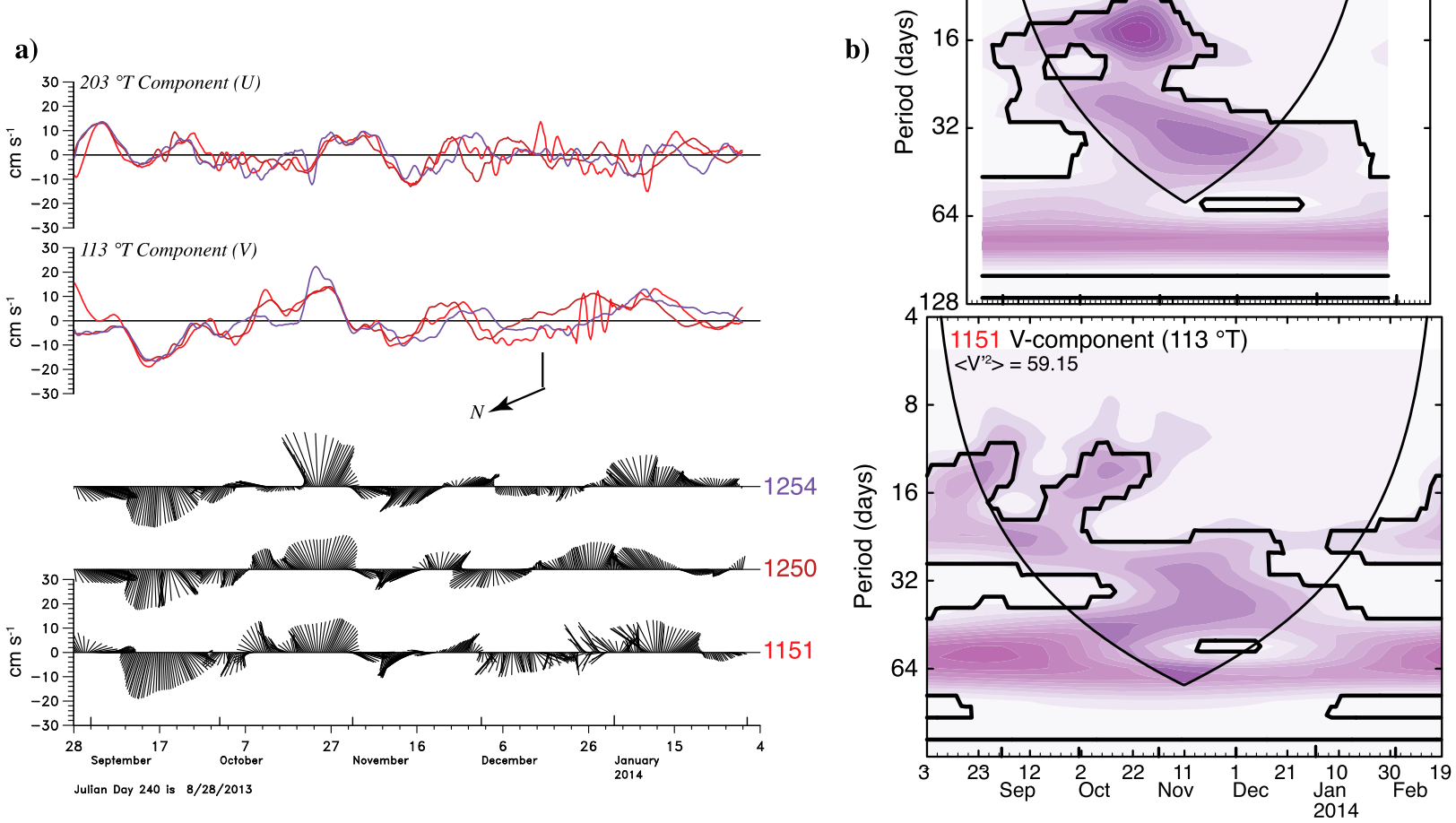

FIG. 11. (a) Velocity vector and component time series from the trajectories of the three 2500-m floats, located south of the Mississippi delta, for the indicated period. For the stick vectors up is $113^{\circ} \mathrm{T}$ (ellipse principal axis in Fig. 9b). (b) The local wavelet power spectra of the $v$ components $\left(113^{\circ} \mathrm{T}\right)$ from floats 1151 and 1254 for the indicated time intervals using the Morlet wavelet normalized by the variances of the respective series. The thick solid contours enclose regions of greater than $95 \%$ confidence for a red-noise process. The lighter shades indicate the "cone of influence" where edge effects become important.

and cyclones is caused by baroclinic instability, and often leads to LC eddy detachments. Characteristics of baroclinic instability are the downstream displacements by a $1 / 4$ wavelength $\left(90^{\circ}\right.$ phase lead) of the deep anticyclones and cyclones from meander crests and troughs, respectively. The EKE is extracted from the available potential energy of the jet (Donohue et al. 2016a), and is the principal process that transfers coherent EKE to the lower layer. Because the lower layer is $\sim 2000 \mathrm{~m}$ thick, the deep EKE is often the dominant portion of the total water column EKE of the LC. Float trajectories were often entrained into deep eddies that were clearly displaced to the south of the corresponding surface jet meander crests and troughs. The trajectory data allowed detailed examination of the structure of individual eddies than was possible from the LC bottom moored currents and PIES array (resolution $\sim 40-50 \mathrm{~km}$ ) analyzed by Donohue et al. (2016a). A particularly good example was the deep cyclone displaced southward from the trough that caused the first detachment of Kraken in March and April 2013. The cyclone was not in solid body rotation, with periods of $\sim 10$ days near the center and $\sim 20-25$ days on the outer edges. Maximum swirl speeds exceeded $25 \mathrm{~cm} \mathrm{~s}^{-1}$, with a diameter of $\sim 150 \mathrm{~km}$ (Fig. 7). Though Donohue et al. (2016a) observed from the LC mapping array that baroclinic instability cyclones and anticyclones moved southwestward across an extended LC, and Furey et al. (2018) showed a similar transit of a cold cyclone from floats, there are almost no observations of deep eddies surviving to the west or northwest of the LC region.

One of the important results of the LC mooring array was that the transfer of EKE to deep flows only occurs intermittently and is associated with meanders and LC eddy detachments (Donohue et al. 2016a; Hamilton et al. 2016a). These episodes only last a few months and there appears to be little transfer of energy, beyond leading edge anticyclones, during the earlier intrusion phase of the LC when meanders are not present. The float velocities confirm this behavior with large increases of deep EKE below the LC for a few months during the detachments of Kraken and Lazarus that, in the case of Kraken, transfers to the west with a lag of a few weeks 

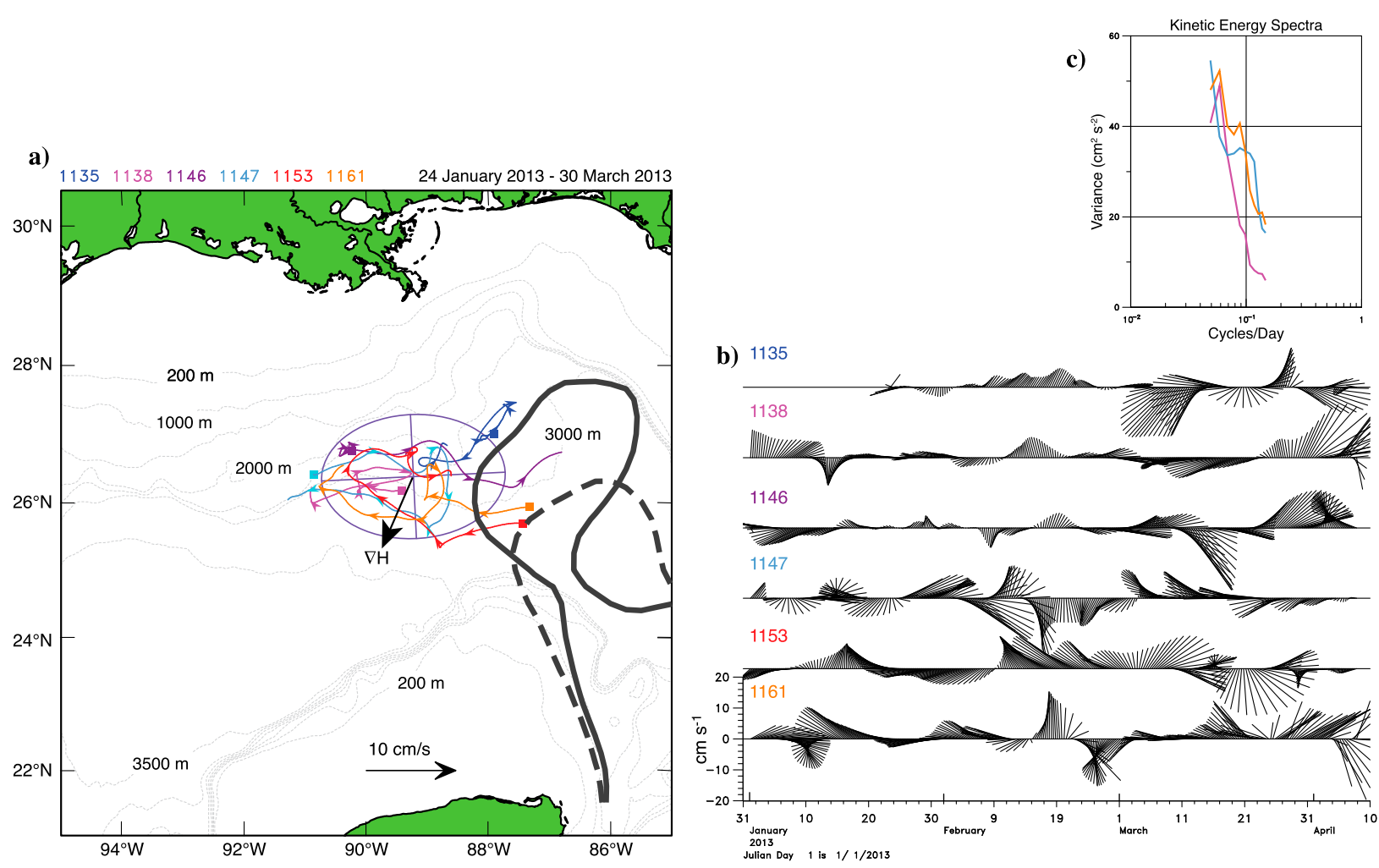

FIG. 12. (a) Blue and red-orange shades for 1500- and 2500-m floats, respectively. For the indicated interval, arrowheads are every 10 days. Initial positions on 24 Jan 2013 marked by solid squares. The location of the 17-cm SSH contour is shown for 24 Jan (dashed) and 30 Mar 2013 (solid thick line). The standard deviation velocity ellipse, centered on the average locations of the floats, is given for the indicated period. The direction of the mean PV gradient is given by the $\nabla \mathbf{H}$ vector. (b) Velocity time series for the floats in (a). Up is north. The bottom two and top three series are at 2500 and $1500 \mathrm{~m}$, respectively. (c) Kinetic energy spectra in variance-preserving form for velocity records from 1138,1147 , and 1161 in (b), color coded by float.

(Fig. 8). A very good example is Lazarus where the deep EKE begins to increase in March 2014 after a long intrusion interval, beginning in October 2013, when deep EKE was small (Fig. 8b). This long interval when there was a retracted LC and no LC eddy activity in the eastern basin showed that the lower layer rapidly becomes fairly quiescent, particularly in the northeast corner of the basin. The floats generally show small oscillations in place with little transport, which is consistent with connectivity calculations that show weak transfers between under the LC, the northeast and the western basin (Hamilton et al. 2016b; Miron et al. 2019). Deep transport between the basins seems to largely occur through the cyclonic boundary current along the steep escarpments (Miron et al. 2019; Pérez-Brunius et al. 2018).

The lack of westward mass transport, coupled with the band of high velocities between the LC and the delta (Fig. 1) strongly favors the transfer of deep EKE from its generation by baroclinic instability under the LC and also under unstable LC eddies (e.g., Kraken after its separation in May 2013; Fig. 2) by TRW radiation. The float trajectory segments of approximately a month outside of the LC or LC eddy tend to be fairly rectilinear (i.e., nonlooping). Large-amplitude, nearly rectilinear oscillations were found west of the LC during and after the detachments of Kraken (January-March 2013), and then 4 months later a little farther west, south of the delta, over 5 months beginning at the end of August 2013. In the latter, three $2500-\mathrm{m}$ floats oscillated rectilinearly in close proximity, showing little dispersion, at small angles to the general trend of the isobaths. This conforms to TRW dynamics very well. Very similar oscillations were analyzed in terms of TRWs by Price and Rossby (1982) for a nine float cluster in the western North Atlantic. The oscillations south of the delta initiated with long periods ( $\sim 60$ days), and then transitioned to $20-25$-day periods with principal axes trending more across the isobaths.

An explanation is that different dispersive wave trains were propagating through this region from different origins (Hamilton 2009), and that the decay of LC deep instabilities through TRW radiation may take 6 months to a year or more. Group speeds of $\sim 60$-day TRWs over typical bottom slopes of the lower Mississippi Fan are $\sim 20 \mathrm{~km} \mathrm{day}^{-1}$, with shorter periods being slower. The long durations and 
spacing of the two sets of observed TRWs implies that the sources in the LC are active for many months and may be dispersed over large areas of the eastern Gulf.

Mean flows under the LC form a west-to-east, anticyclone-cyclone pair similar to that previously observed from the moored current meters of the LC array (Hamilton et al. 2016a). An extended LC tends to lean toward the northwest, so compression and stretching of the lower-layer favors creation of the observed mean flow dipole. However, the anticyclone could also be the result of an accumulation of leading edge anticyclone events. The cyclone is also fed by a boundary current that originates along the eastern Campeche escarpment (PérezBrunius et al. 2018) and flows anticlockwise around the southern and then eastern boundary of the eastern basin.

The major points of this analysis of float trajectories in the eastern Gulf are 1) an advancing LC front, usually during the initial intrusion, develops anticyclones with the compression of the lower layer; 2) baroclinic instability transfers energy to the lower layer when the LC is extended and large-scale meanders are present; 3 ) the large increase in EKE only occupies a few months just prior to and during eddy detachments of the longer LC intrusion cycle; 4) the EKE from these events is transferred from under the LC to the west through TRWs, identified by floats oscillating in the same location over several months as the wave trains propagate toward the delta and the Sigsbee escarpment; 5) the removal of EKE by radiating waves leaves the deep layer of the eastern Gulf relatively quiescent, particularly in the northeast part of the basin; and 6) the mean flow eddy dipole under the LC appears to entrain and/or be partly fed by the boundary current that flows around the Campeche Bank and along the southern and eastern boundary of the basin.

Points 2, 3, and 6 confirm and extend previous results from the LC mapping array (Donohue et al. 2016a; Hamilton et al. 2016a). New results are the development of deep anticyclones under an advancing LC front (point 1), the observation of the decay of deep EKE throughout the eastern basin, after a LC eddy has separated and departed and the LC has retreated to a port-to-port mode (point 4), and evidence that rectilinear TRWs are propagating westward in the region around the Mississippi Fan (point 5). The propagation of TRWs as a mechanism to radiate energy from the under the LC has been previously discussed by Hamilton (2009), but this is the first time they have been described in the Gulf by the relatively stationary oscillations of floats that are similar to the Atlantic observations of Price and Rossby (1982). The radiation of deep EKE from the LC, and its effects on deep circulations farther west, are subjects that need further observations and study. The nature of Lagrangian float observations is that events are often only captured for relatively brief intervals before they disperse to other flows. This type of sampling is illustrated by the deep eddy and TRW circulations observed by this study. However, in recompense for irregular sampling of events, Lagrangian floats are able to provide much greater spatial coverage than is possible from fixed moorings.

Acknowledgments. The authors were supported by the Department of the Interior, Bureau of Ocean Energy Management (BOEM), Contract M08PC20043 to Leidos, Inc., Raleigh, NC. The authors also wish to acknowledge the enthusiastic support of Dr. Alexis LugoFernández, the BOEM Contracting Officer's Technical Representative, during the study into the Deep Circulation of the Gulf of Mexico, using Lagrangian Methods. Thanks go to the captains and crews of the R/V Pelican and B/O Justo Sierra, J. Malbrough (LUMCON), J. Singer (Leidos), J. Valdes (WHOI), B. Guest (WHOI), and the CANEK group (CICESE).

\section{REFERENCES}

Andres, M., J. M. Toole, D. J. Torres, W. M. Smethie Jr., T. M. Joyce, and R. G. Curry, 2016: Stirring by deep cyclones and the evolution of Denmark strait overflow water observed at line W. Deep-Sea Res. I, 109, 10-26, https://doi.org/10.1016/ j.dsr.2015.12.011; Corrigendum, 121, 245-248, https://doi.org/ 10.1016/j.dsr.2017.01.005.

Bower, A. S., and N. G. Hogg, 1992: Evidence for barotropic wave radiation from the Gulf Stream. J. Phys. Oceanogr., 22, 42-61, https://doi.org/10.1175/1520-0485(1992)022<0042:EFBWRF> 2.0.CO;2.

Bunge, L., J. Ochoa, A. Badan, J. Candela, and J. Sheinbaum, 2002: Deep flows in the Yucatan Channel and their relation to changes in the Loop Current extension. J. Geophys. Res., 107, 3233, https://doi.org/10.1029/2001JC001256.

DeHaan, C. J., and W. Sturges, 2005: Deep cyclonic circulation in the Gulf of Mexico. J. Phys. Oceanogr., 35, 1801-1812, https:// doi.org/10.1175/JPO2790.1.

Donohue, K., P. Hamilton, K. Leaman, R. Leben, M. Prater, D. R. Watts, and E. Waddell, 2006: Exploratory study of deepwater currents in the Gulf of Mexico-Volume II: Technical report. Rep. MMS 2006-074, U.S. Dept. of the Interior, 408 pp., https://www.boem.gov/ESPIS/4/4222.pdf.

— D. R. Watts, P. Hamilton, R. Leben, and M. Kennelly, 2016a: Loop Current Eddy formation and baroclinic instability. Dyn. Atmos. Oceans, 76, 195-216, https://doi.org/10.1016/ j.dynatmoce.2016.01.004.

,,,$----\longrightarrow$, , and A. Lugo-Fernández, 2016b: Gulf of Mexico Loop Current path variability. Dyn. Atmos. Oceans, 76, 174-194, https://doi.org/10.1016/j.dynatmoce.2015.12.003.

Furey, H., A. S. Bower, P. Perez-Brunius, R. Leben, and P. Hamilton, 2018: Deep eddies in the Gulf of Mexico observed with floats. J. Phys. Oceanogr., 48, 2703-2719, https:// doi.org/10.1175/JPO-D-17-0245.1.

Hall, C. A., and R. R. Leben, 2016: Observational evidence of seasonality in the timing of Loop Current eddy separation. Dyn. Atmos. Oceans, 76, 240-267, https://doi.org/10.1016/ j.dynatmoce.2016.06.002. 
Hamilton, P., 1990: Deep currents in the Gulf of Mexico. J. Phys. Oceanogr., 20, 1087-1104, https://doi.org/10.1175/1520-0485(1990) 020<1087:DCITGO > 2.0.CO;2.

- 2007: Deep-current variability near the Sigsbee Escarpment in the Gulf of Mexico. J. Phys. Oceanogr., 37, 708-726, https:// doi.org/10.1175/JPO2998.1.

— 2009: Topographic Rossby waves in the Gulf of Mexico. Prog. Oceanogr., 82, 1-31, https://doi.org/10.1016/j.pocean.2009.04.019.

-_, and A. Lugo-Fernandez, 2001: Observations of high speed deep currents in the northern Gulf of Mexico. Geophys. Res. Lett., 28, 2867-2870, https://doi.org/10.1029/ 2001GL013039.

_- K. Donohue, C. Hall, R. R. Leben, H. Quian, J. Sheinbaum, and D. R. Watts, 2014: Observations and dynamics of the Loop Current. Rep. BOEM 2015-006, U.S. Dept. of the Interior, 417 pp., https://www.boem.gov/ ESPIS/5/5471.pdf.

_- A. Lugo-Fernández, and J. Sheinbaum, 2016a: A Loop Current experiment: Field and remote measurements. Dyn. Atmos. Oceans, 76, 156-173, https://doi.org/10.1016/ j.dynatmoce.2016.01.005.

— A. S. Bower, H. Furey, R. Leben, and P. Perez-Brunius, 2016b: Deep circulation in the Gulf of Mexico: A Lagrangian study. Rep. BOEM 2016-081, U.S. Dept. of the Interior, 289 pp., https://www.boem.gov/ESPIS/5/5583.pdf.

- R. R. Leben, A. S. Bower, H. Furey, and P. Perez-Brunius, 2018: Hydrography of the Gulf of Mexico from autonomous floats. J. Phys. Oceanogr., 48, 773-794, https://doi.org/10.1175/ JPO-D-17-0205.1.

Hogg, N. G., 2000: Low-frequency variability on the western flanks of the Grand Banks. J. Mar. Res., 58, 523-545, https://doi.org/ 10.1357/002224000321511007.

Kantha, L., J.-K. Choi, K. J. Schaudt, and C. K. Cooper, 2005: A regional data-assimilative model for operational use in the Gulf of Mexico. Circulation in the Gulf of Mexico: Observations and Models, Geophys. Monogr., Vol. 161, Amer. Geophys. Union, 165-180.

LaCasce, J. H., 1998: A geostrophic vortex over a slope. J. Phys. Oceanogr., 28, 2362-2381, https://doi.org/10.1175/1520-0485(1998) $028<2362$ :AGVOAS $>2.0$.CO; 2 .

_ 2017: The prevalence of oceanic surface modes. Geophys. Res. Lett., 44, 11 097-11 105, https://doi.org/10.1002/2017GL075430.

Leben, R. R., 2005: Altimeter-derived Loop Current metrics. Circulation in the Gulf of Mexico: Observations and Models, Geophys. Monogr., Vol. 161, Amer. Geophys. Union, 181-201.

—_, G. H. Born, and B. R. Engebreth, 2002: Operational altimeter data processing for mesoscale monitoring. Mar. Geod., 25, 3-18, https://doi.org/10.1080/014904102753516697.

Le Hénaff, M., V. H. Kourafalou, Y. Morel, and A. Srinivasan, 2012: Simulating the dynamics and intensification of cyclonic Loop Current frontal eddies in the Gulf of Mexico. J. Geophys. Res., 117, C02034, https://doi.org/10.1029/ 2011JC007279.

Le Traon, P. Y., F. Nadal, and N. Ducert, 1998: An improved mapping method of multisatellite altimeter data. J. Atmos. Oceanic Technol., 15, 522-533, https://doi.org/10.1175/15200426(1998)015<0522:AIMMOM>2.0.CO;2.

Malanotte-Rizzoli, P., N. G. Hogg, and R. E. Young, 1995: Stochastic wave radiation by the Gulf Stream: Numerical experiments. Deep-Sea Res., 42, 389-423, https://doi.org/10.1016/ 0967-0637(95)00001-M.
Miron, P., F. J. Beron-Vera, M. J. Olascoaga, G. Froyland, P. Pérez-Brunius, and J. Sheinbaum, 2019: Lagrangian geography of the deep Gulf of Mexico.J. Phys. Oceanogr., 49, 269290, https://doi.org/10.1175/JPO-D-18-0073.1.

Mizuta, G., and N. G. Hogg, 2004: Structure of the circulation induced by a shoaling topographic wave. J. Phys. Oceanogr., 34, 1793-1810, https://doi.org/10.1175/1520-0485(2004)034<1793: SOTCIB $>2.0 . C O ; 2$.

Nowlin, W. D., Jr., 1972: Winter circulation patterns and property distributions. Contributions on the Physical Oceanography of the Gulf of Mexico, L. R. A. Capurro and J. L. Reid, Eds., Gulf Publishing Co., 3-51.

Oey, L.-Y., and H.-C. Lee, 2002: Deep eddy energy and topographic Rossby waves in the Gulf of Mexico. J. Phys. Oceanogr., 32, 3499-3527, https://doi.org/10.1175/1520-0485(2002)032<3499: DEEATR $>2.0 . \mathrm{CO} ; 2$.

Pedder, M. A., 1989: Limited area kinematic analysis by a multivariate statistical interpolation method. Mon. Wea. Rev., 117, 1695-1708, https://doi.org/10.1175/1520-0493(1989)117<1695: LAKABA $>2.0 . \mathrm{CO} ; 2$.

_ 1993: Interpolation and filtering of spatial observations using successive corrections and Gaussian filters. Mon. Wea. Rev., 121, 2889-2902, https://doi.org/10.1175/1520-0493(1993)121<2889: $\mathrm{IAFOSO}>2.0 . \mathrm{CO} ; 2$.

Pérez-Brunius, P., H. Furey, A. S. Bower, P. Hamilton, J. Candela, P. Carcía-Carrillo, and R. R. Leben, 2018: Dominant circulation patterns of the deep Gulf of Mexico. J. Phys. Oceanogr., 48, 511-529, https://doi.org/10.1175/JPO-D-17-0140.1.

Pickart, R. S., 1995: Gulf Stream-generated topographic Rossby waves. J. Phys. Oceanogr., 25, 574-586, https://doi.org/10.1175/ 1520-0485(1995)025<0574:GSTRW > 2.0.CO;2.

Price, J. F., and H. T. Rossby, 1982: Observations of a barotropic planetary wave in the western North Atlantic. J. Mar. Res., 40 , 543-558.

Rhines, P. B., 1970: Edge-, bottom-, and Rossby waves in a rotating stratified fluid. Geophys. Fluid Dyn., 1, 273-302, https:// doi.org/10.1080/03091927009365776.

Savidge, D. K., and J. M. Bane, 1999a: Cyclogenesis in the deep ocean beneath the Gulf Stream: 1. Description. J. Geophys. Res., 104, 18111-18126, https://doi.org/10.1029/ 1999JC900132.

— and - 1999b: Cyclogenesis in the deep ocean beneath the Gulf Stream: 2. Dynamics. J. Geophys. Res., 104, 1812718 140, https://doi.org/10.1029/1999JC900131.

Schmitz, W. J., Jr., 2005: Cyclones and westward propagation in the shedding of anticyclonic rings from the Loop Current. Circulation in the Gulf of Mexico: Observations and Models, Geophys. Monogr., Vol. 161, Amer. Geophys. Union, 241-261.

Sharma, N., J. S. Storie, K. M. Obenour, M. J. Leber, and A. Srinivasan, 2016: Loop current hyperactivity: Analysis of in situ measurements in the Gulf of Mexico. Offshore Technology Conf., Houston, TX, Offshore Technology Conference, OTC-27229-MS, https://doi.org/10.4043/27229-MS.

Sheinbaum, J., G. Athié, J. Candela, J. Ochoa, and A. RomeroArteaga, 2016: Structure and variability of the Yucatan and loop currents along the slope and shelf break of the Yucatan channel and Campeche bank. Dyn. Atmos. Oceans, 76, 217239, https://doi.org/10.1016/j.dynatmoce.2016.08.001.

Sturges, W., 2005: Deep-water exchange between the Atlantic, Caribbean, and Gulf of Mexico. Circulation in the Gulf of Mexico: Observations and Models, Geophys. Monogr., Vol. 161, Amer. Geophys. Union, 263-278. 
-_, and R. Leben, 2000: Frequency of ring separations from the Loop Current in the Gulf of Mexico: A revised estimate. J. Phys. Oceanogr., 30, 1814-1819, https://doi.org/10.1175/1520-0485(2000)030<1814:FORSFT> 2.0.CO;2.

Thompson, R. O. R. Y., 1977: Observations of Rossby waves near site D. Prog. Oceanogr., 7, 135-162, https://doi.org/10.1016/ 0079-6611(77)90003-9.
Torrence, C., and G. P. Combo, 1998: A practical guide to wavelet analysis. Bull. Amer. Meteor. Soc., 79, 61-78, https://doi.org/ 10.1175/1520-0477(1998)079<0061:APGTWA > 2.0.CO;2.

Walker, N. D., and Coauthors, 2011: Impacts of Loop Current frontal cyclonic eddies and wind forcing on the 2010 Gulf of Mexico oil spill. Monitoring and Modeling the Deepwater Horizon Oil Spill: A Record Breaking Enterprise, Geophys. Monogr., Vol. 195, Amer. Geophys. Union, 103-116. 